\title{
The Theory of Dove-like Particles
}

\author{
SUN Zuodong \\ Ya'ou Brain Science Institute of Heilongjiang Province, Harbin 150090, China
}

\begin{abstract}
Objective: Alzheimer's disease (AD) has been reported for more than 100 years since its first discovery in 1906. There has been no significant progress in the study of its real causes and pathogenesis. The viewpoint of this paper is a heuristic viewpoint based on brain cell activation theory under such background. In this paper, the pathogenesis of sporadic AD is discussed at molecular level by applying the principles of cell physics and biology. The purpose of this paper is to harmonize the existing theories of etiology of $\mathrm{AD}$ and to solve the source problems that have plagued the research field of neurodegenerative diseases for a long time. Method: (1) Discuss the relationship with the existing hypothesis: the A $\beta$ protein hypothesis, the tau protein hypothesis, the presenilin (PS) hypothesis, the apolipoprotein E (ApoE) hypothesis, the cholinergic hypothesis, the inflammatory hypothesis; (2) Demonstration: biophysical proof, medical pathological proof, biological model proof; (3) Interpretation: ion channel and blood-brain barrier, potassium ion and potassium channel, ion pump and epilepsy and cancer, A beta protein and spots and plaques, related AD solutions. Result: (1) Abeta is not the cause of $\mathrm{AD}$, but the remains of brain cells after abnormal apoptosis; (2) The $\mathrm{K}^{+}$ concentration difference of $0.00001 \%$ which causes the great change of membrane potential is the effective concentration, which can not be neglected; (3) Abnormal impairment of potassium channels and early entry of sodium ions to occupy potassium positions are related to epilepsy, cancer and HeLa cells; (4) AD is a physical disease, especially transcranial magnetoelectricity stimulation, should be the first choice for treatment, which can activate abnormal neurons accurately without interfering with normal neurons. Conclusion: (1) Basic contents: excess cations are transferred from extracellular to intracellular. They compete position with potassium ions on the inner surface of cell membranes, thus abatementing the membrane potential, making action potential unable to activate calcium channels normally, which eventually leads to abnormal apoptosis of brain cells. Amyloid plaque is the remains of abnormal apoptotic brain cells. Amyloid plaque is the aggregation of amyloid spots by van der Waals force and electrostatic attraction, and its interstitium is amyloid protein. Brain cells consist of neurons, microglia and astrocytes in turn. Most of the spotted nuclei in the remains are cations. (2) Solutions: the core viewpoint of this paper can be regarded as exploring the etiology of sporadic $\mathrm{AD}$, it is companion volume of Brain cell activation theory, brain cell activation theory is an explanation of the treatment methods and mechanism of neurodegenerative diseases such as $\mathrm{AD}$, it is suitable for encephalopathy but not limited to encephalopathy, the solution of $\mathrm{AD}$ should start with prevention and treatment, the external factor of prevention is environment, especially heavy metal ions, the internal cause is body acidity and alkalinity, physical means, especially transcranial magnetoelectricity stimulation, should be the first choice for treatment. (3) Naming principles: because of the core point of view in this paper-The position of cation occupying potassium is the initiating factor of $\mathrm{AD}$, so the etiology theory is named theory of dove-like particles. Take the Chinese idiom "Turtledove occupies the nest of magpies". "Turtledove" represents the non-essential cation, "magpie" refers to the effective potassium ion, and "nest" refers to the position of the effective potassium ion.
\end{abstract}

Key words: Alzheimer, etiology, cationic placement, amyloid plaque, cell remains, physical mean.

Alzheimer's disease (AD) is one of the most common neurodegenerative diseases. At present, there are about 35.6 million people worldwide, and the aging of the population has led to a sharp increase in the prevalence of AD. The main clinical manifestation of $\mathrm{AD}$ patients is progressive memory impairment. Its

Corresponding author: SUN Zuodong, researcher, post-doctoral co-teacher, research fields: basic theoretical research in brain science and research and development of rehabilitation equipment for severe brain diseases. main pathological feature is the formation of a large number of senile plaques and neurofibrillary tangles in the brain, and diffuse brain atrophy. This feature was described by Aercihaimo as early as 1906. However, for the study of the true etiology and pathogenesis, there has been no significant progress and clear answers in the following 100 years. Research is still between several conjectures and hypotheses.

The viewpoint of this paper is a heuristic viewpoint based on the theory of brain cell activation [1] under 
such background. In this paper, the pathogenesis of sporadic $\mathrm{AD}$ is discussed at molecular level by applying the principles of cell physics and biology. The purpose is to harmonize the existing theories of etiology of $\mathrm{AD}$ and to solve the source problems that have plagued the research field of neurodegenerative diseases for a long time.

Basic contents: Excess cations are transferred from extracellular to intracellular. They compete position with potassium ions on the inner surface of cell membranes, thus abatementing the membrane potential, making action potential unable to activate calcium channels normally [2], which eventually leads to abnormal apoptosis of brain cells. Amyloid plaque is the remains of abnormal apoptotic brain cells. Amyloid plaque is the aggregation of amyloid spots by van der Waals force and electrostatic attraction, and its interstitium is amyloid protein. Brain cells consist of neurons, microglia and astrocytes in turn. Most of the spotted nuclei in the remains are cations.

Cations are classified into inorganic and organic groups. Among them, inorganic cations point to transition metal ions such as $\mathrm{Cu}^{2+}, \mathrm{Zn}^{2+}, \mathrm{AL}^{3+}, \mathrm{Fe}^{2+}$, organic cations refer to $\mathrm{MPP}^{+}$, tetraethylammonium ion (TEA), polyamines, and intracellular proteins below the isopotential point. $\mathrm{MPP}^{+}$is an active organic compound, formed by the catalysis of monoamine oxidase B in glial cells after MPTP enters the brain. MPTP is 1-methyl-4-phenyl-1,2,3,6-tetrahydropyridine, which exists in heroin impurities. Polyamines exist in a positively charged polycationic state and can bind to nucleic acids, proteins and phospholipids in the form of hydrogen bonds and ionic bonds. TEA is a potassium channel impermeable organic cation, but on both sides of the cell membrane, it can block the potassium channel [3-8], which is equivalent to occupying the potassium position.

Alzheimer's disease can be divided into sporadic and familial diseases. It is generally believed that familial $\mathrm{AD}$ has obvious characteristics of familial aggregation, while the pathogenesis of sporadic $\mathrm{AD}$ is still unclear [9]. In this paper, we only focus on the abnormal apoptosis of sporadic AD neurons, no discuss on the neuronal necrosis caused under abnormal physiological conditions such as by physical, chemical or genetic factors. Because of the core point of view in this paper-the position of cation occupying potassium is the initiating factor of $\mathrm{AD}$, so the etiology theory is named Theory of dove-like particles. Take the Chinese idiom "Turtledove occupies the nest of magpies". "Turtledove" represents the non-essential cation, "magpie" refers to the effective potassium ion, and "nest" refers to the position of the effective potassium ion (see Figs. 1 and 2).

$\mathrm{Zn}^{2+} \mathrm{Cu}^{2+} \mathrm{Fe}^{2+}$ is a 2-valent cation, they each occupy two positions of potassium ions, thus counteracting two anions, $\mathrm{Al}^{3+}$ occupies three potassium sites, thus counteracting three anions. Therefore, they reduce the membrane potential and make the action potential unable to activate the $\mathrm{Ca}^{2+}$ channel. Intracellular organelles and cytoplasm "+-" indicate that they are already in a "steady state", accounting for about $99.99999 \%$ of all $\mathrm{K}^{+}$and basically do not participate in membrane potential activities; only $0.00001 \% \quad \mathrm{~K}^{+} \quad$ intra-and intra-membrane communication.

Blue represents the generation of normal membrane potential and the activity of action potential. The red color is the frequency of abnormal neuron's membrane potential and action potential. If the membrane potential was reduced to $50 \%$, the action potential amplitude could not reach the threshold of activating $\mathrm{Ca}^{2+}$ channel. The time of membrane potential depolarization and repolarization may be reduced from $2 \mathrm{~ms}$ to $1 \mathrm{~ms}$, the frequency of invalid action potential release will be doubled, and the ATP energy consumed by sodium-potassium pump will also be doubled. 


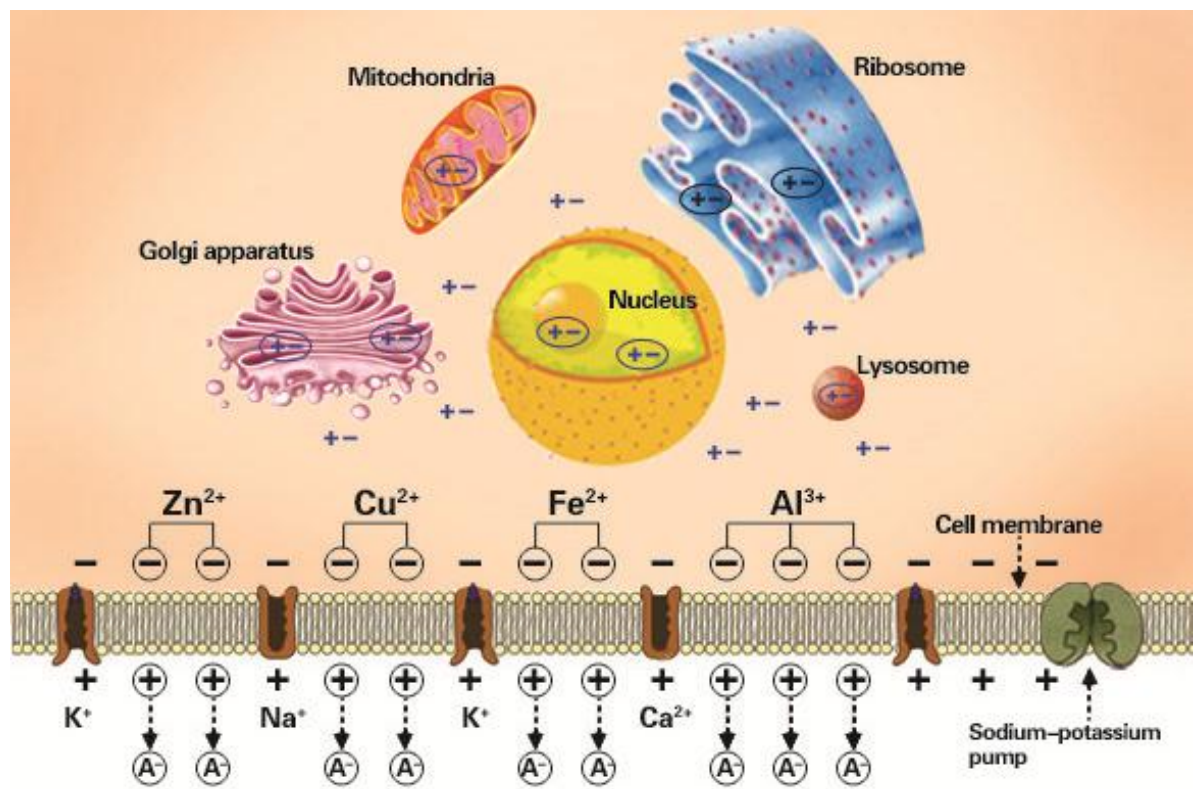

Fig. 1 Cation occupies potassium position principle.

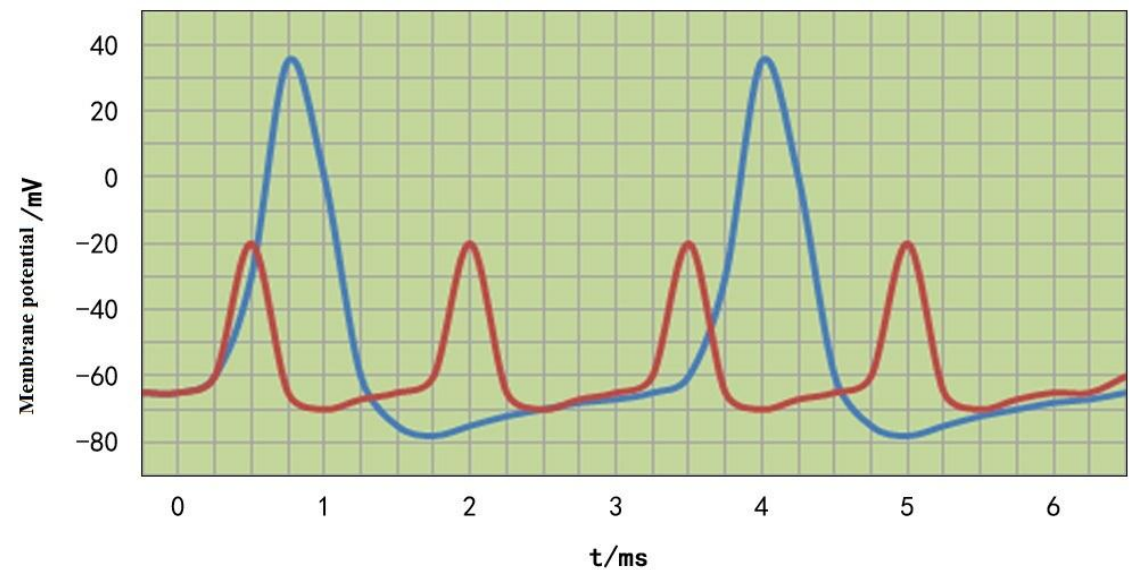

Fig. 2 Occupying potassium and affecting action potential.

\section{Relationship with Hypothesis of A $\beta$, tau,} etc.

The theory of etiology of AD mainly includes the $A \beta$ protein hypothesis, the tau protein hypothesis, the presenilin (PS) hypothesis, the apolipoprotein E (ApoE) hypothesis, the cholinergic hypothesis, the inflammatory hypothesis, the metal ion metabolism disorder hypothesis, etc. Among them the more mainstream views are the accumulation of $A \beta$ protein and the hyperphosphorylation of Tau protein.

\subsection{Aß Protein Hypothesis}

The A $\beta$ protein hypothesis [10-12] holds that the formation and accumulation of senile plaques is the main cause of $\mathrm{AD}$. The main component of senile plaque is beta-amyloid polypeptide $(A \beta)$, consisting of a group of 39-43 amino acid residues, which is a peptide segment produced by APP after enzymatic digestion. $\mathrm{A} \beta$ is derived from amyloid precursor (APP), it is a normal product of APP metabolism in all nervous system cells [13]. Under normal conditions, 
the production and degradation of $A \beta$ are balanced. Drug research based on this hypothesis focuses on reducing the production of $A \beta$, increasing the clearance of $A \beta$ or blocking the aggregation of $A \beta$. For more than 30 years, no truly effective drug has been available [14].

Therefore, some scholars believe that $A \beta$ is not the primary and main mechanism of pathological damage in $\mathrm{AD}$, but only the pathological marker accompanied by pathological damage in $\mathrm{AD}$ [15]. The opinion is also controversial that they may, to some extent, aggravate the pathological damage of AD. That is, if amyloid is harmful, knocking out or inhibiting these proteins in multiple sclerosis mice should alleviate the disease, but studies have shown that these measures only aggravate the condition of mice.

The researchers point out that $A \beta$ is actually synthesized by the organism to protect itself, which is very common in the organism. These proteins act as molecular chaperones, helping to clear harmful molecules associated with inflammation and immune response near the site of injury.

In addition, the mechanism of $\mathrm{A} \beta$ toxicity also derived many auxiliary hypotheses, such as $A \beta$ fiber aggregation hypothesis [16, 17], receptor mediation hypothesis [14], microglia mediation hypothesis [18], neuronal axoplasmic transport disorder hypothesis [19], endoplasmic reticulum-associated protein-A $\beta$ complex toxicity hypothesis [20,21], etc. This makes the problem of AD more complex and difficult, which does not conform to the principle of simplicity of a scientific hypothesis.

Three Masterpieces of The Starry Night: Sarry Night over the Rhone, Starry Night Over the Rhone, The Cafe Terrace on the Place du Forum, let the reader imagine and express his wisdom-Infinite universe, mysterious brain, Alzheimer $A \beta$ spots and plaques. Unfortunately, this genius lived only 37 years. He sold only one painting in his lifetime and was forced to go to a psychiatric hospital, but left behind nearly 2,000 world-famous paintings.
Recently, researchers have found that APP gene encoding beta-amyloid precursor in neurons of $\mathrm{AD}$ patients undergoes a large number of rearrangements and mutations. Some of these mutations are unique to $\mathrm{AD}$ patients [22]. It seems to provide new evidence for the $A \beta$ protein hypothesis. The meaning of this article is: research in the past decades has not been in vain and can be used as a new way of thinking for clinical drug development.

The $A \beta$ protein hypothesis has led researchers into a strange circle of silence cost effect, seems to have reached the point of "too big to fail". One of the main points of this paper is to reverse the causal relationship between excessive $\mathrm{A} \beta$ and $\mathrm{AD}$.

\subsection{Tau, PS, ApoE Hypothesis}

According to the tau protein hypothesis [23-25], abnormal phosphorylation and aggregation of tau protein are the main causes of $\mathrm{AD}$. Tau protein is the main microtubule protein in nerve cells, which participates in microtubule assembly and stabilization of synaptic transmission mechanism. Normal tau protein is a phosphorus-containing protein. The phosphoric acid content of tau protein per gram molecule is 2-3 grams. In AD patients, the phosphoric acid content of tau protein per gram molecule is 5-9 grams, which is $2-3$ times the normal level. When tau protein is over-phosphorylated and aggregated in cells, it can inhibit the assembly of microtubules and destroy the stability of microtubules, thereby damaging the axonal transport system, resulting in synaptic loss and retrograde degeneration.

The abnormal tau protein plays an important role in the pathogenesis of $\mathrm{AD}$. It also participates in the pathological process of more than 20 other neurodegenerative diseases, some scholars believe that abnormal tau protein is the upstream event of $A \beta$.

According to PS Hypothesis [26, 27], PS may play a role in the pathological process of $\mathrm{AD}$ by regulating gamma-secretase to cleave APP and affect tau protein phosphorylation. PS includes PS-1 (467 amino acids) 
and PS-2 (488 amino acids), which are highly homologous. PS is involved in the regulation of intracellular calcium signaling pathways, such as adjust the stability of beta-catenin, transport of membrane proteins and calcium-dependent apoptosis. About $50-80 \%$ of familial AD is associated with PS-1 and PS-2 gene mutations.

According to the ApoE hypothesis [28-30], ApoE acts similarly to neurotrophic factors. It is abundant in senile plaques of $\mathrm{AD}$ patients and it also exists in intracellular neurofilament tangles (NFT) caused by tau hyperphosphorylation [15]. So far, ApoE is the only known apolipoprotein closely related to the nervous system, it consists of 299 amino acid residues with a molecular weight of $34 \mathrm{KD}$. ApoE is the most important lipid transporter in the central nervous system, which is mainly produced by astrocyte. At the beginning of nerve regeneration, a large number of lipids accumulated in the injured area, macrophages in the stroma migrated to the injured area, synthesized and secreted ApoE to capture liposomes and store them in macrophages. The lipids carried by ApoE will be used for axonal and myelin regeneration.

Tau, PS and ApoE only have effect on the ascending or descending pathway of beta-amyloid, although it has attracted the attention of researchers, but Like $A \beta$, it belongs to the late event of degeneration of $\mathrm{AD}$ neurons.

\subsection{Cholinergic Hypothesis}

According to the cholinergic hypothesis [31, 32], that the loss of cholinergic neurons in basal forebrain and enzyme activity decreased significantly is the most prominent pathological and neurochemical feature of $\mathrm{AD}$ patients, it is the main cause of learning and memory impairment in $\mathrm{AD}$ patients.

This hypothesis is widely supported by the evidence of pharmacology, biochemistry and electrophysiology, this hypothesis is also supported by the author himself in the brain cell activation theory [1], but in the theory of brain cell activation, it seems that the expression of "it is an indisputable fact that the selective degeneration of cholinergic neurons in the brain" does not rigorous enough. The reason for degeneration of cholinergic neurons in the brain is the special location of concentrated area of cholinergic neurons in brain_-basal forebrain, instead of "selective degeneration". Take this opportunity to correct the inappropriate expression of brain cell activation theory.

The cholinergic hypothesis can only explain the mechanism of $\mathrm{AD}$ memory impairment, but it is not inconsistent with this paper, and is completely covered by this paper view.

\subsection{Inflammation Hypothesis}

According to the inflammation hypothesis [33, 34], inflammatory factors are the main factors leading to degeneration of $A D$ neurons. Neuritis is a prominent feature of $\mathrm{AD}$ brain, inflammation in the brain of $\mathrm{AD}$ patients is the activation of microglia and astrocytes. It is embodied in its number increased, volume increased, initiative enhanced, secretion of a variety of inflammatory factors. At present, it is widely believed that the immune response of these inflammatory factors is closely related to the pathological progress of $\mathrm{AD}$ [35-37]. Microglia account for about 5\%-20\% of the total number of glial cells, they are macrophages in the brain and the only immune cells in the brain parenchyma, therefore, it is regarded as the first line of defense of the central nervous system against pathogenic invasion.

The view of this article is that the inflammatory factors are not the initial factors leading to degeneration of $\mathrm{AD}$ neurons, it is the normal immune response of microglia to beta-amyloid spots and plaques, it's probably beneficial and harmless.

\subsection{Metabolic Disorder Hypothesis of Metal Ions}

According to the metal ion hypothesis [38], metabolic imbalance of metal ions in brain is related to $\mathrm{AD}$, iron and copper deficiency maybe mainly 
closely related to the early stage of $\mathrm{AD}$, iron and copper plasma overload maybe mainly closely related to $\mathrm{AD}$ late damage, the importance of this theory in the development of $\mathrm{AD}$ research has attracted wide attention of researchers.

Four red elements, accounting for $99 \%$ of the total number of human atoms; seven blue elements, accounting for $0.9 \%$ of the total number of human atoms; other elements of green labeling are also essential trace elements for human body. At present, it is not clear whether the yellow marking elements are necessary for the human body, the essential trace elements of human body should not exceed the standard excessively, if excessive extracellular potassium ions affect the membrane potential, sodium ions will prematurely mix into the cell and occupy the potassium position.

This paper supports some of the viewpoints of this theory, the difference is that: the cations mentioned in this paper are not limited to inorganic metal cations, but also include organic cations. In this paper, the author applied the principles of biophysics to explain the pathogenesis, this theory applies biochemical principles such as oxidative stress reaction and is incompatible with other theories (see Fig. 3).

\section{Demonstration}

Although this article does not support or not fully support the theories of various etiologies of $\mathrm{AD}$, however, the basis of these theories can be transformed into a natural conclusion as evidence to support this point of view.

\subsection{Biophysical Proof}

During the action potential process, the depolarization of cells is caused by the transmembrane influx of sodium ions, and the repolarization of cells is caused by the outflow of potassium ions, it was confirmed by Hodgkin and Huxley experiments: the ascending phase of action potential is caused by the instantaneous increase of $\mathrm{g}_{\mathrm{Na}}$ and the influx of sodium ions, and the descending phase is related to the increase of $g_{K}$ and the outflow of potassium ions [39-41].

A small change in $\mathrm{K}^{+}$concentration can cause a great change in membrane potential. Using Nernst equation, the relationship between ion concentration and equilibrium potential was calculated for a cell with a diameter of $50 \mu \mathrm{m}$ and a diameter of 100 $\mathrm{mmol} / \mathrm{L} \mathrm{K}^{+}$, the results show that the change of the membrane from $0 \mathrm{mV}$ to $-80 \mathrm{mV}$, its need concentration change is about $0.00001 \mathrm{mml} / \mathrm{L}$, when $\mathrm{K}^{+}$outflow reached equilibrium, intracellular $\mathrm{K}^{+}$ concentration decreased from $100 \mathrm{mmol} / \mathrm{L}$ to $99.99999 \mathrm{mmol} / \mathrm{L}$, which was one-tenth of a million $(1 / 10,000,000)[42]$.

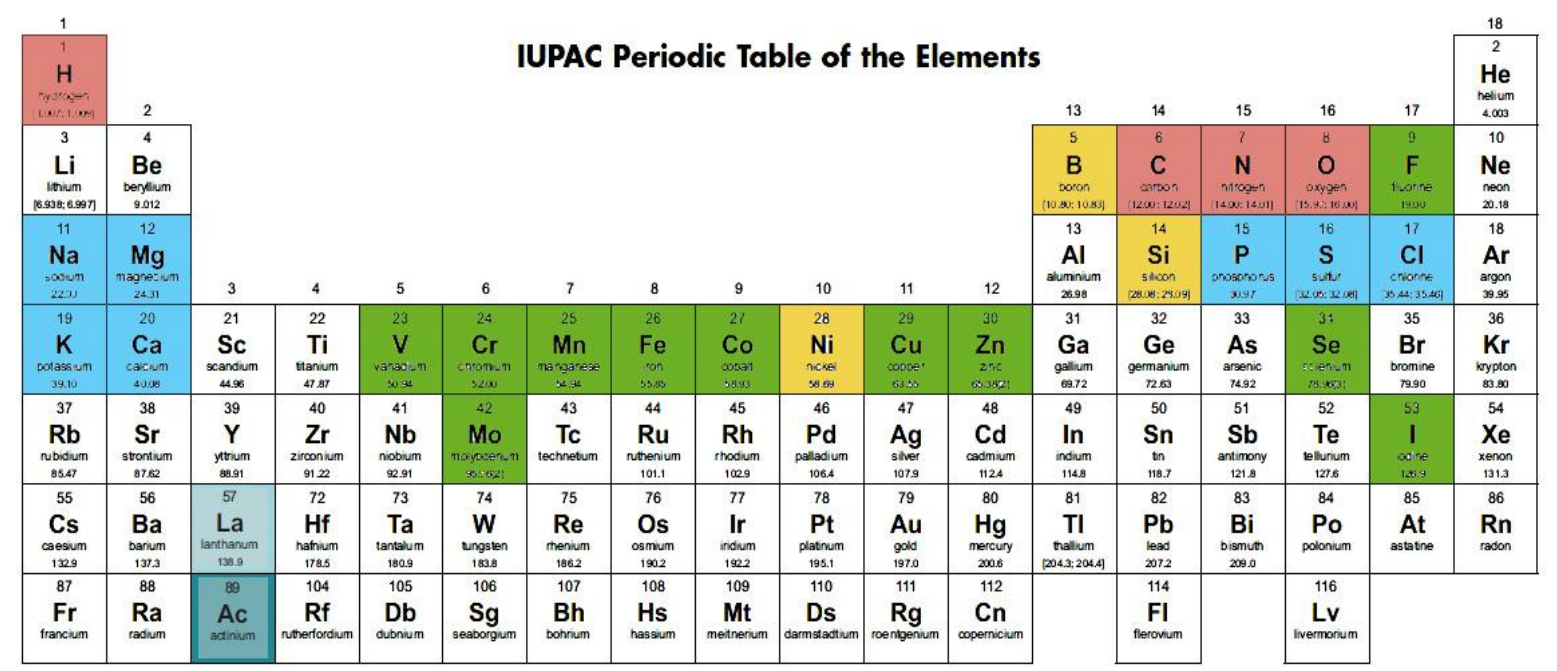

Fig. 3 Essential trace elements in human body. 
Nernst equation: $E_{\text {ion }}=2.303 \frac{\mathrm{FT}}{\mathrm{ZF}} \log \frac{[\text { [ion] }}{[\text { [ion }]_{\mathrm{i}}}$

$E_{\text {ion }}$ : Ion Equilibrium Potential; R: Gas constant; $T$ : Absolute temperature; Z: Ionic charge; F: Faraday constant; Log: Logarithm with base 10; [ion]。: Extracellular ion concentration; [ion] $]_{\mathrm{i}}$ Intracellular ionic concentration. Under the condition of body temperature, the Nernst equation of $\mathrm{K}^{+}$can be simplified as follows:

$$
\begin{aligned}
& E_{\mathrm{K}}=61.54 \mathrm{mV} \log \frac{\left[\mathrm{K}^{+}\right]_{0}}{\left[\mathrm{~K}^{+}\right]_{\mathrm{i}}} \mathrm{IF} \frac{\left[\mathrm{K}^{+}\right]_{0}}{\left[\mathrm{~K}^{+}\right]_{\mathrm{i}}}=\frac{1}{20} \text { and } \\
& \log \frac{1}{20}=-1.3
\end{aligned}
$$$$
\text { Then } E_{\mathrm{K}}=61.54 \mathrm{mV} \times(-1.3)=-80 \mathrm{mV}
$$

Cells $50 \mu \mathrm{m}$ in diameter:

Cell volume $V=\frac{4}{3} \pi R^{3}=65,416.66667 \mu \mathrm{m}^{3}$

Surface area $S=4 \pi R^{2}=7,850 \mu m^{2}$

Then, how many $\mathrm{K}^{+}$does this concentration difference of one in ten million correspond to? We then deduce that: $1 \mathrm{~L}=10^{15} \mu \mathrm{m}^{3}$, amount to $6 / \mu \mathrm{m}^{3}$, the $\mathrm{K}^{+}$efflux from the whole cell was $393,808 \approx$ 400,000 , equivalent to the inner surface of the membrane $50 / \mu \mathrm{m}^{2}$. If there are $2,000 \mathrm{~K}^{+}$channels in a single neuron, a $\mathrm{K}^{+}$channel can be shared at $4 \mathrm{um}^{2}$. That is to say, for an action potential stroke, there are only $200 \mathrm{~K}^{+}$outflows or inflows per $\mathrm{K}^{+}$channel.

In theory, the permeability of a potassium channel is per second through $10^{8}$ potassium ions [43], the actual results are as follows: the change of membrane potential from $0 \mathrm{mV}$ to $-80 \mathrm{mV}$ requires only $\mathrm{K}^{+}$ Concentration Change one in ten million, amount to 400,000 per time, $50 / \mu \mathrm{m}^{2}, 6 / \mu \mathrm{m}^{3}, 200 /$ passageway. Generate an action potential, single ion channel outflow or transfer to $\mathrm{K}^{+}$, it is not really a big number, but in terms of the structure and function of cells, this number hides great secrets.

Only the concentration difference of $0.00001 \%$ is the effective concentration. $\mathrm{K}^{+}$is aggregated on the surface of the cell membrane or a small amount of free organelles. It really participates in the activity of membrane potential, the remaining $99.99999 \%$ of potassium ions, counteract the negative charges on intracellular anions or organic molecules and are in a "steady state". They exist in the nucleus and organelles of cells, and a small part of them are stable between the fine organelles. Compared with the generation of membrane potential, they can be regarded as invalid concentration. Therefore, the ratio of activation rate of specific ions cannot be equal to the ratio of concentration. Applying Nernst equation, using the Ratio Method of Concentration, it can be deduced that the relationship between the change of membrane potential and the change of $\mathrm{K}^{+}$ concentration is not very close [44]. But it did not respond to the "one in ten million" question.

Any cation, if $\mathrm{K}^{+}$flows out of the cell, will leave an uncoupled negative charge in the cell, from this, this produced an electric field or a membrane potential, this membrane potential prevents further extracellular migration of $\mathrm{K}^{+}$, they reached a balance in about $1 \mathrm{~ms}$ [45]. In other words, any non-essential cations that are incorporated into the cell and remain on the surface of the endothelium will counteract the negative charge on the inner surface of the membrane. At this time, nonessential cations have occupied the position of potassium ions, and affected the amount of $\mathrm{K}^{+}$ transported by the sodium-potassium pump from the outside to the inside of the cell. If it is a bivalent cation, one cation will cancel out two negative charges and replace two $\mathrm{K}^{+}$. Taking $\mathrm{Zn}^{2+}$ as an example, about $85 \%$ of $\mathrm{Zn}^{2+}$ ions in the brain bind to metalloproteins and remain stable, while about $15 \%$ of $\mathrm{Zn}^{2+}$ ions are free. The density of $\mathrm{Zn}$ is $7.14 \mathrm{~g} / \mathrm{cm}^{3}$, and is greater than $4.5 \mathrm{~g} / \mathrm{cm}^{3}$, therefore, $\mathrm{Zn}^{2+}$ is easily deposited on the surface of endothelium, it competes with the potassium ion on the inner surface of the membrane and occupies the position, which will greatly reduce the membrane potential, when a certain threshold is reached, the action potential generated by it will not activate the voltage-gated $\mathrm{Ca}^{2+}$ channel, which will eventually lead to neuron apoptosis and abnormal death. The effect of excessive cation occupying 
potassium position on membrane potential, it is inaccurate to use the term "membrane depolarization" to express.

Similarly, membrane potential is also sensitive to changes in extracellular potassium concentration, if the change of extracellular $\mathrm{K}^{+}$concentration 10 times, that is, the increase of $\mathrm{K}^{+}$concentration from 5 $\mathrm{mmmol} / \mathrm{L}$ to $50 \mathrm{mmol} / \mathrm{L}$, will make the membrane change from $-65 \mathrm{mV}$ to $-17 \mathrm{mV}$ [42], it results in more than $70 \%$ changes in membrane potential.

The above values are only estimates, the estimated values of different editions of textbooks differ greatly $[44,45]$, but they all clearly express such a view, that is: $\mathrm{K}^{+}$, which is used to establish cell membrane potential and enter the charged layer, has no significant effect on intracellular $\mathrm{K}^{+}$concentration [44], its concentration one in ten million change can be neglected [42]. This is the key point that the author tries to correct and reminds researchers to attach great importance to: the current algorithm of Nernst equation cannot really reflect the relationship between effective ion concentration and membrane potential, the concentration difference of one in ten millions is the effective concentration, which should never be neglected, this is the key to the problem.

\subsection{Medical Pathological Proof}

At present, it can be determined that beta-amyloid protein is a biomarker for $\mathrm{AD}$ detection [15]. A large number of studies have shown that: there are a lot of amyloid proteins in the brain neurons of AD patients, which accumulate to form senile plaques, it coexists with high concentration of metal ions, including zinc (about $1 \mathrm{mmol} / \mathrm{L}$ ), copper (about $0.4 \mathrm{mmol} / \mathrm{L}$ ), aluminum (about $0.88 \mathrm{mmol} / \mathrm{L}$ ), iron (about 0.9 $\mathrm{mmol} / \mathrm{L}$ ), etc. [46-50].

Autopsy of patients with advanced AD found that, zinc content in hippocampus, amygdala and multiple neocortex increased significantly [51-56]. Using atomic absorption spectrometry (AAS) and micro-PIXE (micro-PIXE), the researchers confirmed that zinc content in the senile plaques of $\mathrm{AD}$ patients was up to $1,055 \mathrm{mmol} / \mathrm{L}$, while zinc content in the nerve fiber network of the same age control group was only $350 \mathrm{mmol} / \mathrm{L}$ [57]. Dong et al. [58] separated the senile plaques of $\mathrm{AD}$ patients, observed and determined their structure and composition by Rman microscopy, and found that the distribution of zinc ions was consistent with that of histidine residues. Rehga et al. [59] detected the content of zinc ion in the cortex of autopsy of $10 \mathrm{AD}$ patients and 14 controls of the same age, he found that the content of zinc ion in the cortex of $\mathrm{AD}$ patients was more than twice that of the control group. The level of zinc ion in the cortex of most advanced AD patients increased significantly. Using metal autoradiography, it is found that zinc ions accumulated in a large number of $A \beta$ plaques $[60,61]$, especially in the nucleus $A \beta$ of neuroinflammatory plaque congregated in dysfunctional neuronal processes, a large amount of zinc ion deposition can also be seen in the site of amyloid angiopathy [60, 62]. In the vulnerable sites of $\mathrm{AD}$ lesions, such as hippocampus and amygdale, it can be detected that abnormal elevation of zinc ion concentration [51-56, 63]. In vitro studies have shown that zinc ion can induce hyperphosphorylation of Tau protein [64]. The increase of zinc ion in the brain of patients with advanced $\mathrm{AD}$ is consistent with the appearance of neurofibrillary tangles, in the neurons with neurofibrillary tangles, and zinc ion content increased significantly [65]. In vitro studies showed that treating it with zinc ion of 300-600 micromol/L for 15 minutes, can cause extensive neuronal death in the cerebral cortex [66].

The recommended intake of copper was $0.9 \mathrm{mg} / \mathrm{d}$. The healthy human body contains $110 \mathrm{mg}$ of copper, while the brain contains about $9 \mathrm{mg}$ of copper. Appropriate amount of copper is of great significance to the human body. The concentration of free copper in normal cells is less than 1 atom per cell on average [67, 68]. Maynard et al. [69] found that the level of copper ion in brain tissue increased significantly with 
age, the concentration of $\mathrm{Cu}^{2+}$ in senile plaques was very high (about $0.4 \mathrm{mmol} / \mathrm{L}$ ) [70]. Lovell et al. [71] used particle emission (PIX) to measure the content of copper ions in the brain of $\mathrm{AD}$ patients, which was 1.5 times than that of normal people. Atwood et al. [72] reported that the concentrations of copper, iron and zinc in senile plaques of $\mathrm{AD}$ patients were 390 $\mathrm{micromol} / \mathrm{L}, 940 \mathrm{micromol} / \mathrm{L}$ and 1,055 micromol/L, respectively, which were significantly higher than those of the control group (70 micromol/L, 340 micromol/L and $350 \mathrm{micromol} / \mathrm{L}$ ), the concentration of cerebrospinal fluid in AD patients increased by 2.2 times compared with the normal level, accompanied by changes in copper, iron and zinc-related proteins.

Aluminum is not necessary for human body, but the research results show that the incidence of $\mathrm{AD}$ in individuals with chronic aluminum poisoning is as high as $71 \%[73,74]$. As early as 1973 , Crapper et al. [75] found that aluminium accumulated in some areas of the brain of $\mathrm{AD}$ patients and could induce degeneration of nerve fibers in higher animals. In 1980, Perl and Brody [76] used scanning electron microscopy (SEM) and X-ray fluorescence spectroscopy (XRF) to detect the content of $\mathrm{Al}$ in hippocampal neurons of $\mathrm{AD}$ patients and normal elderly cadavers respectively. The results showed that the content of $\mathrm{Al}$ in neurons with high percentage of neuronal fiber tangles increased significantly in both $\mathrm{AD}$ patients and normal elderly people, while there was almost no $\mathrm{Al}$ deposition in adjacent normal neurons. Yumoto et al. [77] used energy diffraction $\mathrm{X}$-ray spectroscopy and transmission electron microscopy (TEM-EDX) to investigate the role of aluminium in the brain of $\mathrm{AD}$ patients. The results showed that aluminium participated in the process of $\mathrm{A} \beta$ aggregation to form neurotoxic fibers, and may induce $A \beta$ to form $A \beta$-folding structure. Gonzalez-Dominguez et al. [78] have studied the dynamic balance of metals in the pathogenesis of $\mathrm{AD}$. The results show that Al-mediated neurotoxicity mainly acts on small molecule substances. Moreover, the abnormal concentration of $\mathrm{Al}$ in blood also affects the distribution of other metal elements and disturbs the dynamic balance of metals in serum. It has been proved that reducing the intake of aluminium is an effective measure to prevent AD [79].

Although iron ion has no direct interaction with $\mathrm{A} \beta$, the iron content in $\mathrm{AD}$ patients' brain is positively correlated with the development of disease. With the increase of age, iron ions deposit in the globus pallidus, caudate nucleus and putamen nucleus, mainly in the globus pallidus, this should be the direct evidence of the "Amyloid spots are the remains of abnormal apoptotic brain cells" view. The researchers also found an abnormally high concentration of $\mathrm{Fe}^{3+}$ in senile plaques (about $1 \mathrm{mmol} / \mathrm{L}$ ) [70]. Zhu et al. [80] discovered that, the iron content in bilateral hippocampus, parietal lobe, shell, caudate nucleus and dentate nucleus in the brain of $\mathrm{AD}$ patients was significantly higher than that of the normal control group. Brar et al. [81]'s research results show that accumulation of iron will add to the pathogenesis of AD.

\subsection{Proof of Biological Model}

Metal ions can cause $\mathrm{AD}$, which has been confirmed by a large number of basic experiments by researchers at home and abroad, in particular, AD animal models have been successfully made with metal ions, which supports the core point of this paper as strong evidence.

Genghai Bureau and Luo Huanmin [82] succeeded in preparing $\mathrm{AD}$ animal model on the basis of subacute aging model with D-galactose and aluminium trichloride, the model mice showed obvious learning and memory impairment, decreased levels of acetylcholine (ACh), decreased activities of acetylcholinesterase (ChAT) and cholinesterase (CHE), and pathological changes such as senile plaques and neurofibrillary tangles. Kawahara et al. [83] used primary cultures of mouse cerebral cortical neurons as a model system in vitro to study the 
accumulation and neurotoxicity of aluminium to $A \beta$, they found that three weeks after adding $50 \mathrm{mmol} / \mathrm{L}$ aluminium chloride, neurons changed morphologically and accumulated A $\beta$. They also used Western blotting to detect the polymerization of $A \beta$ in vitro, it demonstrates that aluminium induces conformational changes of $A \beta$ peptide and enhances the accumulation of $A \beta$ in vitro. Cheng et al. [79] studied the rat of $\mathrm{AD}$ model induced by aluminium, it is confirmed that excessive intake of aluminium causes the imbalance of cholinergic system in rats and leads to AD. She found that the acetylcholinesterase (AchE) activity in rat hippocampus was significantly increased, ChAT activity was significantly decreased, and ACh content was significantly reduced in the diet group containing medium and high doses of aluminium.

Walton et al. [84] fed rats with $\mathrm{AlCl}_{3}(1.7 \mathrm{mg} / \mathrm{kg} \bullet \mathrm{d})$ for 4 months and found that the expression of APP gene in hippocampus and cortex increased. Rui et al. gave ICR mice oral $\mathrm{AlCl}_{3}(10 \mathrm{mg} / \mathrm{kg} \bullet \mathrm{d})$ for 100 days, it was found that MDA levels in hippocampus and cortex increased, SOD activity decreased, and DNA oxidative damage occurred in hippocampus and cortex neurons. Adult male Wistar rats were fed oral $\mathrm{AlCl}_{3}$ $(17 \mathrm{mg} / \mathrm{kg} \cdot \mathrm{d})$ for 6 weeks to induce AD-like pathology. Compared with the control group, the model group rats showed glial cell activation and neuronal atrophy. Justin et al. [85] injected $\mathrm{AlCl}_{3}(100$ $\mathrm{mg} / \mathrm{kg} \bullet \mathrm{d}$ ) intraperitoneally for 60 days in male Wistar rats, there were significant learning and memory deficits and increased neuronal apoptosis in rats. Rodella et al. [86] fed mice with $2.5 \%$ aluminium sulfate solution for 12 months, amyloid vasculopathy similar to precipitation of $A \beta$ appeared in mice. The deposition of $\mathrm{A} \beta$ protein in hippocampus and cortex increased significantly. The mice were fed with $\mathrm{AlCl}_{3}$ $(60 \mathrm{mg} / \mathrm{kg}$ ) for 7 days. Compared with AD model mice by step-through test, the ability of spatial memory and learning in $\mathrm{AD}$ model mice was decreased.
Copper can also aggravate the pathological changes of AD. Some researchers used bilateral carotid artery ligation combined with high $\mathrm{Cu}^{2+}$ feeding to induce the establishment of $\mathrm{AD}$ rat model, it was found that in the Morris test, the escape latency time of model group was significantly delayed compared with that of control group only with bilateral carotid artery ligation, the structure similar to senile plaque also appeared, in the cortex and hippocampus, the positive cells of A $\beta$-like immunoreaction [87] were produced. Hutchinson et al. [88] also confirmed that copper ion levels did increase in transgenic mice. Sparks [89] fed rabbits a high cholesterol diet and added trace amounts of copper $(0.12 \mathrm{ppm})$ to their drinking water, results compared with the control group fed distilled water under the same conditions, the formation of senile plaque increased significantly, and closer to human age plaques, at the same time, cognitive impairment occurred in rabbits.

Wang [90] fed AD transgenic mice with high iron drinking water, it aggravates the deposition of $A \beta$ and phosphorylation of tau protein in the brain. Wang et al. [91] also found that, long-term use of drinking water with high zinc content in APP/PS1 transgenic mice resulted in increased expression of APP and splitting, and deposition of $A \beta$ in the brain.

\section{Explanation}

We assume that the above viewpoints and arguments are correct, on this premise, it is necessary to discuss some issues closely related to the core viewpoints of this paper one by one. Even if some arguments are insufficient or not direct enough, they may also be mentioned as side evidence of this viewpoint.

\subsection{Ion Channel and Blood Brain Barrier}

Ion channels require 4 to 6 similar protein molecules to polymerize, and a channel is formed in the center. Although there are hundreds of ion channels, most of them have ion selectivity, this is 
determined by the diameter of the channel and the properties of the $\mathrm{R}$ group inside the channel, channel proteins can be suspended in lipid bilayers, its hydrophobic part is located in the membrane, while its hydrophilic ends are exposed to the water environment both side [92-95]. Blood-brain barrier refers to the barrier between plasma and brain cells formed by brain capillary wall and glial cells, and between plasma and cerebrospinal fluid formed by choroid plexus, these barriers prevent certain substances from entering brain tissue from the blood, it is difficult or easy for many solutes in blood to enter brain tissue from brain capillaries: Some of them passed quickly, some slowly, and some could not pass at all [96-98].

\subsubsection{Relativity of Transparent Selection}

Their permeability and selectivity are derived from evolution, and their selectivity to ions is relative. Taking potassium channel [2] as an example, the pore size of selective filter and molecular composition determine the selectivity of channels to potassium ions [99-102]. The atomic radii of potassium ion and sodium ion are $1.33 \AA$ and $0.95 \AA$ [43], respectively, although sodium ions are smaller than potassium ions, however, potassium channels can effectively select potassium ions to pass through, one third of the potassium channel is a selective filter, it determines the specificity of ion selection. There are four potassium ion binding sites in the potassium channel, although sodium ion is smaller than potassium ion, it cannot interact with oxygen atoms lining the channel, so it cannot effectively pass through the potassium channel. Similarly, the permeability of sodium channel to sodium ion is more than 12 times higher than that of potassium ion, most of the binding water is removed when sodium ions pass through the channels, the remaining water molecules act as ion chaperones to help sodium ions pass through selective filters, this ion-water complex can be used to select sodium ions and remove potassium ions.

It has been reported that when 20 potassium ions pass through the channel, one sodium ion passes through the channel [103]; another document is expressed in this way: the permeability of potassium channels to potassium is one thousand times that of sodium ions, that is to say, only one sodium ion may be mixed into of the 1,000 potassium ions passing through [104]; Another document provides the following data: the ionic radius of $\mathrm{Na}^{+}$is much smaller than that of $\mathrm{K}^{+}$, but its permeability is less than one in ten thousand one of $\mathrm{K}^{+}$[105].

There are many similar life science textbooks, the data provided on the same question are very different, for example, the data difference of radius of $\mathrm{Na}^{+}$and $\mathrm{K}^{+}$ions, and the data error of permeability selectivity of potassium ions, etc. it is really embarrassing for the students. Let us compromise, the permeability of potassium channel to sodium ion is tentatively set at $0.01-5 \%$. Although the data are so different, it also illustrates the fact that the selectivity of ion channels is not absolute.

The sensitivity of membrane potential to potassium ion concentration leads to the evolution of the regulation mechanism of intracellular and extracellular potassium concentration. One of them is the blood-brain barrier, which restricts potassium and other blood loads from entering the brain's extracellular body fluids, it also includes other non-essential cations, especially metal ions. Once excessive potassium ions break through the blood-brain barrier, it can also be dispersed into a larger area by the network of astrocyte processes, the mechanism by which astrocytes regulate intracellular potassium concentration is called potassium spatial buffering [106-108].

Using copper ions as an example, in physiological state, capillaries prevent them from entering the brain. Over time, excessive copper ions enter the cerebral vessels through the blood circulation and deposit on the walls of the vessels, it is especially deposited on endothelial cells of capillaries. These cells are the key components of the blood-brain barrier of the brain 
defense system, which regulate molecules into and out of brain tissue [109]. Excess copper ions must have broken through the blood-brain barrier, otherwise, it cannot explain the source of copper ions in brain tissue, so the permeability selectivity of blood brain barrier is relative.

\subsubsection{Cationic Pathway into Brain}

Cations can be absorbed by nerve tissue through blood-brain barrier, choroid plexus and nasal cavity [110]. Some channel proteins are highly selective and allow only one ion to pass through; other channel proteins allow several homologous ions with the same valence to pass through; some channel proteins are completely random [111].

There are 12 pairs of nerves in and out of the brain, only the olfactory nerve is exposed [14]. The olfactory nerve begins in the olfactory mucosa of the nasal cavity. The central processes of the olfactory cells first merge and interlace into clusters in the mucosa, and then synthesize 15 to 20 olfactory filaments from the clusters. The olfactory filament leaves the olfactory mucosa and enters the anterior cranial fossa through the ethmoidal foramen upward, terminating in the olfactory bulb [112]. This is also why some patients with increased intracranial pressure may have leakage of cerebrospinal fluid from the nasal cavity.

The degeneration and death of dopaminergic neurons in the substantia nigra of patients with Parkinson's disease (PD) may be related to their long-term exposure to volatile substances or special environment, it is because of the special location of the substantia nigra in the brain and the exposure of the olfactory nerve. One is that substantia nigra is located in the center of the brain, and the probability of obtaining non-essential cations is much higher than that of other parts of the brain. The other is that it is directly related to the exposed olfactory nerve. Ulla et al. [113] examined the substantia nigra and caudate putamen nucleus of PD patients by magnetic resonance imaging, and found obvious iron deposition, which was related to the severity of the symptoms.
Olfactory dysfunction is the first clinical symptom of PD patients, which occurs earlier than motor symptoms, but is easily ignored by patients and doctors. Other studies have shown that about $80 \%$ of patients with PD will develop into dementia in the late stage, namely Parkinson's dementia (PDD). Severe olfactory dysfunction can be used as an important clinical indicator of the asymptotic development of PDD [114].

The above facts are sufficient to illustrate that, unnecessary cations may enter neurons through more than one pathway, because it is a trace element or non-essential element, there are no special channels and transporters for it in the process of life evolution.

\subsubsection{Intracellular Location of Cations}

Cations are also called positive ions. It refers to the ionic form that loses the outer electrons to achieve a relatively stable structure, inorganic refers to transition metal ions. Organic cations tend to point to large and small carbon molecules, any protein has a characteristic $\mathrm{PH}$, called isoelectric point $(\mathrm{pH}=7$ without any charge), it is positively charged below the isoelectric point and can directly occupy the position of potassium in the cell (see Fig. 4).

There is relatively weak electrostatic attraction between polar covalent bond molecules. Any macromolecule containing many polar groups has positive charges in part of its surface and negative charges in the other part. When such a molecule encounters another molecule with anisotropic charge, they attract each other by electrostatic attraction, when a large number of non-covalent bonds are formed on the surface of two macromolecules, they will adhere to each other specifically. Moreover, the non-charged polar side chains cannot be ignored, for example, in neutral $\mathrm{PH}$, although $\mathrm{N}$ of amide is not charged, it is polar.

The reason why non-essential cations can "travel long distances" to the central nervous system and invade neurons is determined by the characteristics of their free state. Because, more similar cations, for 

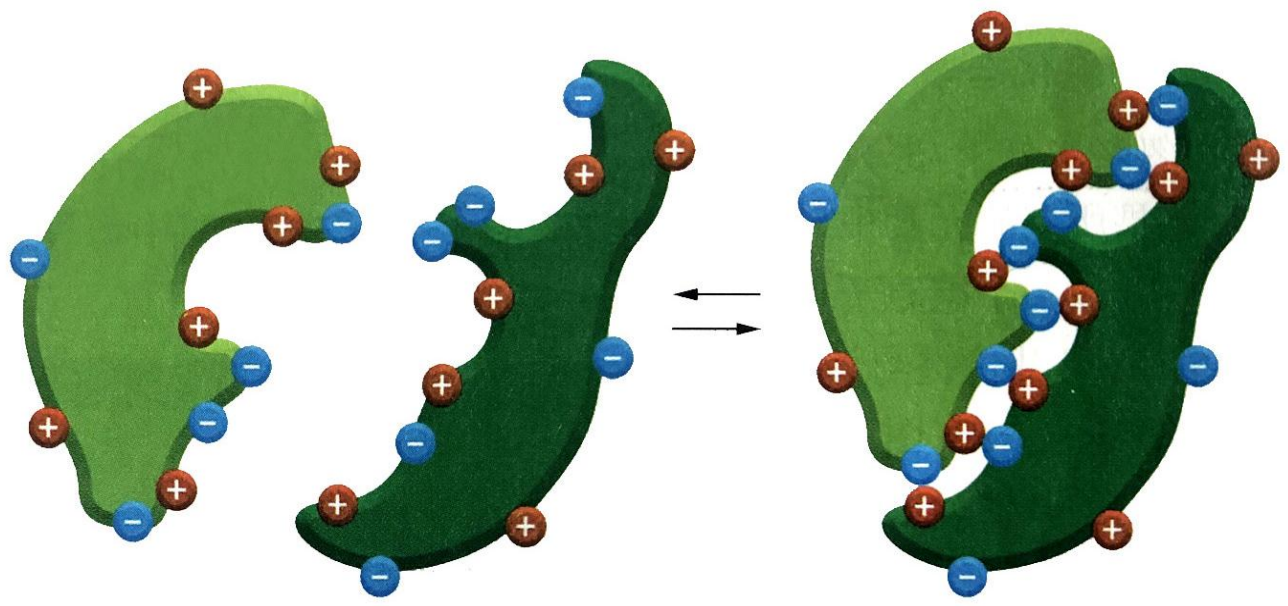

Fig. 4 Proteins and other macromolecules bind to each other through complementary charges on their surfaces.

example, zinc is about $85 \%$, it is intercepted at the initial stage of entry into the body, it is stable in combination with other negative substances, only a few cations (about $15 \%$ zinc) wander around. On the way, even encounter with other negative substances is a temporary virtual combination, will not really be in a "steady state".

Once such cations, especially metal ions, enter neurons, their density determines their landing point, which is deposited on the inner surface of cell membranes. Cations entering the cell are involved in the production of membrane potential, although their role is negative. The nucleus is often pushed to the edge of the cell by the central organelle, this increases the probability that metal ions will break into the nucleus again, this is one of the main reasons why the nucleus is the target of most metal ions, the consequence of its entry into the nucleus is a mutation or canceration of the gene. Luckey [115] thought that the nucleus seemed to be the main target of most carcinogenic metals and cited examples that HEATH found that carcinogenic metals mainly existed in the nucleus.

After cations enter the nucleus and organelles, we can think of it as a "steady state", it can be understood as a "metal ion library", the cations in the free state precipitated on the inner surface of the membrane and participated in the activity of the membrane potential.
It is very difficult for non-essential cations to break through the blood-brain barrier. If they escape the screening of ion channels again and break into cells, it is very, very difficult. In theory, the probability of cations entering the cell nucleus or organelle again is almost the same as that of cations escaping from the cell, for all that, it still increased its chances of attacking the nucleus. Metal ion transporters (DMT1) exist on the surface of many neuron membranes in the brain, it is shared by many divalent metal ions and can transport $\mathrm{Fe}^{2+}, \mathrm{Zn}^{2+}, \mathrm{Mn}^{2+}, \mathrm{Co}^{2+}, \mathrm{Cd}^{2+}, \mathrm{Cu}^{2+}, \mathrm{Ni}^{2+}$, $\mathrm{Pb}^{2+}$, etc. For all that, once excessive non-essential metal ions enter cell, the transport capacity of DMT1 will not meet the actual needs and become very active. When non-essential cations enter the cell, they occupy the position of potassium and play a destructive role, it does not occupy sodium and calcium ions, even if this happens, it is of no real significance.

In addition, cations block or destroy ion channels. Inward rectifier $\mathrm{K}^{+}$channel is another form of $\mathrm{Kv}$ or Shaker channel. This rectification phenomenon is caused by the blockage of ion channels and the loss of outward potassium current caused by positive charged $\mathrm{Mg}^{2+}$, Spd in cell membrane depolarization [116, 117]. Under physiological conditions, polyamines exist in a positively charged polycationic state, polyamines can intercalate ion channels on membranes to prevent ions from transporting into and out of cells, especially the 
blocking or interference of polyamines on $\mathrm{Ca}^{2+}$ and $\mathrm{K}^{+}$ channels, if all potassium channels can be blocked by TEA [118, 119], then the signal transmission process will be significantly affected [120-125], which is equivalent to indirectly occupying the position of potassium. TEA can bind at different sites and channels on both sides of the membrane to block potassium channels $[4,6,8,56,126]$.

Blood-brain barrier and ion channel, its permeability and selectivity are not absolute, gating of ion channels is also not absolute. Another important property of ion channels is gated, channels of this nature can be opened and closed. Because there are channels in the cell membrane of neurons, as long as the volume of metal ions in the extracellular fluid is smaller than the pore size of the pore, they are easy to diffuse or mix into the cell with the influx of ions, no matter in what form and whether it is fat-soluble or not.

Recently, Scientific American reported the research of Thomas Heimburg and other scientists, it is believed that neurons communicate with each other through mechanical waves similar to sound waves, while electrical impulses are only by-products of this process. Because the energy of acousto-optoelectronic magnetocaloric heat can be converted to each other, and eventually the configurations of ion channels can be changed by mechanical force, so there is nothing wrong with understanding the transmission of action potentials as mechanical waves.

\subsection{Potassium Ions and Potassium Channels}

For cellular neurobiology, the most important ions are monovalent cationic sodium and potassium, bivalent cationic calcium and monovalent anionic chlorine. Among them, potassium ions are ions obtained by the loss of one outermost electron of the potassium atom, it is the main cation of intracellular fluid, in our bodies, $98 \%$ of potassium is found in cells. Normally, the potassium content in the daily diet is enough to meet the needs of the body, and there will be no potassium deficiency, the distribution of potassium ions in different concentrations inside and outside cells is an important reason for the formation of negative membrane potential. Potassium channels are also involved in regulating the electrical activity of various cells, it also determines the frequency of action potential, amplitude, mode of repetitive discharge activity.

Simply put, an objective index for evaluating cell viability and death is whether there is a negative membrane potential in the cell, so the importance of potassium ion and potassium channel is self-evident, it can also be understood as the starting point and end point of action potential generation and release.

So how does potassium channel achieve its selective permeation mechanism? This is due to the structural study of the potassium channel (KcsA potassium channel) of Streptomyces, it has amino acid sequences similar to those of other potassium channels [101, 102, 127, 128], especially in the pore region which contains the characteristic sequence of potassium channel in the membrane, it has almost the same sequence as Drosophila shaker channel and vertebrate voltage-gated potassium channel $[129,130]$. By studying on the interaction between KcsA Potassium Channel Toxin and Eukaryotic Potassium Channel Toxin, it is confirmed that its pore area is similar to that of eukaryotic organisms, and this structure remains unchanged when the channel is separated from the membrane [131]. The structure of KcsA potassium channel is consistent with the results of the study of shaker channel function and mutation, its concept of pore zone is defined on the basis of the study of the role of scorpion venom and channel [132], this inhibitor interacts with the amino acid residues outside the pore membrane [133, 134].

When the gated selectivity of potassium channels decreases due to external force damage or gene mutation, a large number of sodium ions will "mix" into cells ahead of time from potassium channels, after that it is transported to extracellular space by 
sodium-potassium pump. If sodium ions occupy the potassium position in this way, destroying neurons [42], its behavior is very covert, although it is cationic with copper and zinc, it is not easily detected. Without exception, all potassium channels have a key amino acid sequence, that is, the characteristic sequence of potassium channels. Let the amino acids in this sequence mutate, that would deprive the potassium channel of its ability to distinguish between potassium and sodium ions [7, 42, 126] and causes sodium and potassium ions to pass through channels.

Yuh-Nung Jan and Lily Yeh Jan revealed abnormal potassium channels in the shaker mutant. Abnormal impairment of potassium channels, that would increase sodium permeability and decrease the negative value of neuronal membrane potential, it eventually leads to neuronal apoptosis [135, 136]. Once the potassium channel is damaged, even without the involvement of non-essential cations such as copper, zinc, aluminium and iron, premature neuronal apoptosis can be induced, at this time, sodium ions entering ahead of time compete with potassium ions to occupy positions. This shows the importance of potassium channels.

\subsection{Ion Pump}

In cellular neurophysiology, two ion pumps are particularly important: sodium-potassium pumps and calcium pumps, both of which are enzymes. The function of sodium-potassium pump is to exchange sodium ions in the membrane with potassium ions outside the membrane, so as to ensure that potassium ions gather inside neurons, and sodium ions gather outside neurons [137-139]. The function of calcium pump is to transport calcium ions from intracellular to extracellular [140-142]. The function of ion pump is to form ion concentration gradient, which needs to consume metabolic energy [143-147]. It is estimated that the human brain consumes $20 \%$ of its total energy, the sodium-potassium pump consumes $70 \%$ of the brain energy.

\subsubsection{Ion Pump and Epilepsy}

The intracellular occupancy of non-essential cations shortens the time course of action potential generation and membrane repolarization, this increases the frequency of invalid action potential and induces epilepsy.

In fact, the incidence of epilepsy in AD patients was more than 10 times higher than that in non-AD patients of the same age [148], Nelson et al.'s study [149] showed that aged plaques and neurofibrillary tangles also exist in temporal lobe epilepsy, the first description and nomenclature of amyloid plaques originated from epileptic patients. Palop et al. [150] implanted human amyloid precursor protein (hAPP) gene into mouse brain, video EEG monitoring revealed frequent cusp waves and spike waves in the hippocampus and cortex of mice, especially in the brain where hAPP and beta are deposited. Intermittently, mice appear simple partial seizures and complex partial seizures associated with hippocampus. Scarmeas et al. [151] found that, $\mathrm{AD}$ is an independent risk factor for epilepsy, the incidence of epilepsy in $\mathrm{AD}$ patients is higher than that in the general population; A-matniek et al. [152] found that the younger patients with $\mathrm{AD}$ had epileptic seizures at the early stage of the course. Scharfman [153] found that, hippocampal sclerosis can lead to neuronal loss, but it has little effect on dentate gyrus neurons, it eventually leads to the number and function of excitatory neurons in this area being greater than that of inhibitory neurons, this disturbs the balance of electrical activity. Hall et al.'s [154] study found that, because the dendrites of hippocampal neurons are overexcited, they express excessive $\mathrm{A} \beta$, this overexcitation of dendrites is related to the loss of Kv4.2. Levetiracetam, an antiepileptic drug, can prevent the loss of Kv4.2 channel. In the treatment of $\mathrm{AD}$ patients with epilepsy, it is important to improve cognitive function [154].

\subsubsection{Ion Pump and Cancer}

When the organism's tissue grows and renews itself, 
the cell must maintain its proper specific properties, occupy its proper position, and not invade where it should not go. Potential catastrophic failures occur when a cell violates its basic rules.

The occurrence of cancer is such an accident: Ignoring the normal constraints of proliferation, invade other cell territory. Taking copper ion as an example, we set it as normal that intracellular copper ion is less than or equal to 10, if copper ions actually intrude 100, after four splits, it has fallen to normal level, it reduces the concentration of unnecessary cations, as long as the copper ion source is cut off in time, the tumors should be benign. Normal somatic cells divide about 50 times, normal people's physiological endurance is not able to adhere to it fission 50 times. During this period, if the following events occur, canceration will occur, that is, benign tumors become malignant tumors: first, potassium channels are destroyed by copper ions, for example, a shaker mutant was produced, a large number of sodium ions flow into the cells through potassium channels to occupy the position of potassium, which seriously reduces the membrane potential; second, invalid action potential was released at high frequency, and sodium-potassium pump excessive consumed energy released by ATP; third, copper ions invade the nucleus and change the DNA base sequence, resulting in unconstrained cell proliferation. Somatic cells are different from neurons, as highly specialized cells, mature central neurons no longer have the ability to divide and proliferate.

Faced with such a situation, even if no excess copper ions can be detected in cancer cells, sodium ion will replace copper ion to occupy potassium position and continue to disturb, cells that continue to divide and proliferate compete with normal cells for energy and living space. Applying this point of view, it can also reasonably explain the "immortality" of HeLa cells. It may be caused by the damage of potassium channel caused by Shaker mutant, the alteration of DNA base sequence in cell nucleus and the position of sodium ion occupying potassium ion in culture medium [105].

In fact, external factors are responsible for only a small number of cancer mutations. In one's life, about $10^{16}$ cell divisions occur in the body, therefore, each individual gene may be mutated when more than $10^{9}$ cells divide. From this point of view, it seems that the problem of cancer is not why it happens, but why it happens less. In fact, cancer belongs to ion channel disease, as same as AD, PD, epilepsy and arrhythmia, cancer cells may not be evil in nature, it proliferates, invades and transfers in order to avoid cationic occupancy. It is a stress response that does not want to die, it is the $\mathrm{N}$ expression of the will to do good, but unfortunately we have not listened carefully to its voice.

\subsection{Aß Protein, Spots and Plaques}

In 1984, Glenner and Wong [155] purified and isolated $A \beta$ from senile plaques and interpreted its protein sequence. Normally, $A \beta$ in the central nervous system is mainly produced by neurons, which are cleared by phagocytosis, enzymatic degradation and receptor transduction [156]. Later, it was found that activated astrocytes could also produce $\mathrm{A} \beta$. In $\mathrm{AD}$, activated astrocyte aggregates around senile plaques $[157,158]$.

Astrocytes can also uptake and internalize $A \beta$ [159-161] in the extracellular environment. For example, $A \beta$ [162] can be detected in astrocytes in the brains of $\mathrm{AD}$ patients, astrocytes were cultured on brain slices of A D mice containing $A \beta$. It was found that astrocytes could bind to senile plaques and reduce the total content of $A \beta$ in these slices $[163,164]$. Astrocytes also secrete a variety of inflammatory factors, especially microglia, it is considered to be the only immune cell in the brain parenchyma [162].

Our results support the view that $A \beta$ is a normal product of APP metabolism in all nervous system cells, and that amyloid spots are the remains of abnormal apoptotic brain cells, amyloid plaque is the 
aggregation of amyloid spots by van der Waals force and electrostatic attraction. The interstitium is amyloid protein. Brain cells in turn contain neurons, microglia and astrocytes, the spotted nuclei of its remains are mostly cations, nucleus-free remains can be absorbed, digested and transported by glial cells, during this period, autophagy is also one of the cell's options for better survival.

The formation of amyloid spots is similar to formation of pearls, the formation of amyloid plaques is similar to formation of corals also, corals are made up of numerous anthozoan remains. From this we infer that, normal people also have hundreds of millions of "spots" in their brains, like the stars in the night sky, shining with golden "light".

The formation of amyloid spots is similar to formation of pearls, the pearls formed by foreign bodies such as sand intruding into the shell of mussel have nuclei, the pearls formed by pathological changes or injuries are seedless, AD amyloid spots can be absorbed by glial cells. For nucleated amyloid spots, glia may be powerless and sacrificed. The formation of amyloid plaques is similar to formation of corals, corals are made up of numerous anthozoan remains.

We also believe that, in the pathophysiological process of $\mathrm{AD}, \mathrm{A} \beta$ deposition is a protective mechanism of organism, the release of inflammatory factors by microglia is a stress response to protect nerve tissue. Therefore, deliberate removal of such "spots" and "patches" may be of no practical significance or even worse.

In the development of new drugs, a vaccine for removing amyloid plaques from brains of $\mathrm{AD}$ patients is very effective in removing plaques, but it does not prevent the deterioration of the nervous system caused by the disease. Vaccines can be reduced or even completely eliminated plaque, but the patient's symptoms have not been improved accordingly. Lawrence Steinman et al. [165] showed that although some amyloid fragments (including tau and prion) form fibers, these fibers can quickly alleviate neurodegenerative symptoms in mice, and in some cases $\mathrm{A} \beta$ is beneficial. Clinical pathological studies have found that some people with extensive senile plaques in the brain have no dementia.

\subsection{Solutions to $A D$}

The core idea of this article is that the non-essential cation occupies the potassium position in the cell, which is the initial factor of AD. If so, the solution of $\mathrm{AD}$ should start with prevention and treatment, the external factor of prevention is environment, especially heavy metal ions, the internal cause is body acidity and alkalinity, proteins in acidic constitution cells are positively charged. Physical means, especially transcranial magnetoelectricity (weak magnetic field) stimulation, should be the first choice for its treatment, the optimal target is voltage-gated calcium channel, followed by the exocytosis of excess cations. Its aim is to fundamentally block the apoptotic process of neurons and activate neurotransmitters. Cations are highly sensitive to electromagnetic fields, for neurons that are transferred from excitation to inhibition, they can be reactivated again, conventional chemical methods will not do as well, such diseases should be classified as Physiotherapy diseases.

At present, the treatment of chemical means is mainly to treat amyloid plaque or inflammatory factors as a target, this may not be a wise choice, such as metal ion chelating agents, oligosaccharide inflammatory inhibitors, thiamine (vitamin $\mathrm{B}_{1}$ ), etc. Its actual effect will not be stronger than that of $\mathrm{AD}$ adjuvant drugs such as cholinesterase inhibitors and glutamate receptor antagonists.

Metal ion chelating agents are a class of organic or inorganic compounds, which form stable water-soluble complexes by chelating metal ions [166-168], first of all, it is necessary to be able to pass the screening of blood-brain barrier, such as lipid-soluble small molecule compounds, secondly, 
the corresponding metal ions are required to have low affinity, otherwise they will destroy the ionic homeostasis and normal function of the body [169, 170], at the same time, it should be non-toxic, efficient and easy to be discharged from the body [171], these conditions are very harsh, at present, chloriodohydroxyquine (CQ) [172] is the most widely studied one, it has no effect on intracellular metal ions. Inflammatory inhibitor, is an inflammatory factor released by the immune response of microglia, as mentioned earlier. Such inflammatory factors may be beneficial or harmless, if it must be inhibited, only non-steroidal anti-inflammatory drugs can be taken. Epidemiological data indicate that, long-term use of non-steroidal anti-inflammatory drugs can reduce the incidence of $\mathrm{AD}$, the risk of disease was reduced by 60-80\%. Non-steroidal anti-inflammatory drugs can reduce the activity of microglia, for example, ibuprofen could significantly reduce the level of $A \beta$ senile plaque and brain $A \beta$ in $\operatorname{Tg} 2576$ mice [14], similar results were obtained in APP mice treated with different non-steroidal anti-inflammatory drugs. In addition, some people use oligosaccharides to hunt amyloid proteins to eliminate $A \beta$ in the brain, some scholars have clearly pointed out that such "sugar pills" eat or not is the same.

In addition, some researchers have used ultrasound as a means to open the blood-brain barrier, consequently, the consequences are injury of innocent neurons and destruction of blood-brain barrier, that would be a big loss. Deep brain stimulation (DBS) and high intensity repetitive transcranial magnetic stimulation (rTMS) can damage the brain if not handled properly, its fault is not only a disaster for patients, but also a bad influence on the development of medical science, the highest principle of medicine is no harm, additional damage from treatment is not allowed [1]. What is more needed is protection for neurons and blood-brain barriers, not all physical means can be used to treat encephalopathy.

\subsubsection{AD, PD Clinical Trial}

In our study group, 80 patients with mild to moderate $\mathrm{AD}$ underwent a double-center, randomized, double-blind, parallel, placebo-controlled 8-week clinical trial, there were 40 cases in the treatment group and 40 cases in the control group, the test results show that: transcranial magnetoelectric encephalopathy treatment instrument has good therapeutic effect for treatment mild to moderate alzheimer's disease. It can improve the mental state, cognitive behavior and self-care ability of daily life [173, 174] (see Table 1).

In our study group, 22 patients with mild to moderate PD were observed for 20 days by double-center, randomized, double-blind and self-cross-control method, the results showed that the transcranial magnetic computerized therapy instrument could significantly improve the symptoms of resting tremor, stiffness and motor retardation in patients with PD, and it was safe to use [175, 176] (see Table 2).

The above conclusion data, were approved by the State Drug Administration respectively. It also serves as part of the clinical basis for the certification and registration of Parkinson Therapeutic Instrument (2011) and Alzheimer Therapeutic Instrument (2014).

\subsubsection{Animal Test of Epileptic Mice}

Our study group also discussed the curative effect of transcranial magnetic stimulation therapy on hyaluronic acid temporal lobe epilepsy mice [177-183]. Sixty-two rats were randomly divided into pretreatment group (32 rats) and treatment group (30 rats). The pretreatment group was further divided into four groups, and the treatment group was further divided into three groups, 10 in each group, the stimulation was observed for 14 days, the changes of behaviour, electrophysiology and histology in three groups of rats were recorded and compared to evaluate the effect of transcranial magnetic stimulation therapy on epileptic rats. 
Table 1 Differences of scales between treatment group and control group after 8 weeks of treatment (after treatment-before treatment) Scoring results $(x+s$, score), test statistics $(t$ value) and $p$ value group.

\begin{tabular}{llllll}
\hline Group & Number & MMSE & ADAS & CDR & ADL \\
\hline treatment group & 40 & $1.58 \pm 1.53$ & $-1.78 \pm 1.68$ & $-0.14 \pm 0.32$ & $1.63 \pm 3.47$ \\
control group & 40 & $0.28 \pm 1.45$ & $-0.03 \pm 1.53$ & $-0.04 \pm 0.17$ & $0.00 \pm 3.00$ \\
Test statistics & & 3.895 & -4.812 & -1.734 & 2.242 \\
$p$ & & 0.0002 & $<0.0001$ & 0.0880 & 0.0278 \\
\hline
\end{tabular}

Table 2 Comparison of total effective rate and total effective rate in different stages between two groups (PPS and FAS).

\begin{tabular}{lllllllll}
\hline \multirow{2}{*}{ Grouping } & \multicolumn{3}{c}{ Analysis 10 days after treatment } & \multicolumn{3}{c}{ Analysis 20 days after treatment } & \multicolumn{2}{c}{ Total apparent } \\
\cline { 2 - 7 } & Number & $\begin{array}{l}\text { Total apparent } \\
\text { efficiency }\end{array}$ & $\begin{array}{l}\text { total effective } \\
\text { rate }\end{array}$ & Number & $\begin{array}{l}\text { total effective } \\
\text { rate }\end{array}$ & $P_{1}$ & $P_{2}$ \\
\hline Group A & 11 & $45.45 \%$ & $72.73 \%$ & 11 & $36.36 \%$ & $81.82 \%$ & 0.0351 & 0.0010 \\
Group B & 11 & 0.00 & 0.00 & 11 & $18.18 \%$ & $45.45 \%$ & 0.6351 & 0.1827 \\
\hline
\end{tabular}

Note: $P_{1}$ : Chi-square test of total apparent efficiency; $\mathrm{P}_{2}$ : Chi-square test of total effective rate; $P$ value: UP was the result of analysis 10 days after treatment; DOWN was the result of analysis 20 days after treatment.

RESULTS AND CONCLUSION: 50\% MCI was the best stimulus intensity. The frequency of mouse epileptic waves in epileptic stimulation group was significantly lower than that in non-stimulation group $[(30.210 \pm 4.580) / \mathrm{min}$ vs. $(31.380 \pm 4.247) / \mathrm{min}]$, the difference has statistical significance $(t=3.235, p=$ 0.001). Timm staining results showed that there were significant differences in staining scores among the three groups and has statistical significance, the Timm staining score in the dentate gyrus of hippocampus in the epileptic stimulation group was significantly lower than that in the non-epileptic stimulation group, the difference has statistical significance $(P<0.05)$. Transcranial magnetic stimulation therapy can affect the formation of dentate gyrus neuronal circuits by improving the histological changes of the molecular layer in the dentate gyrus of hippocampus in epileptic rats, to reduce the frequency of epileptic EEG seizures (see Table 3 and Fig. 5, Fig. 6).

In Fig. 6, the black arrow shows colored zone. After 14 days of TMES treatment in epileptic rats, we evaluated the effect of TMES on MFS with Timm score. The results showed that there was no Timm staining band in the dentate gyrus of the hippocampus in the control group, while the inner molecular layer of the dentate gyrus of the hippocampus in the non-stimulating epilepsy group showed a black Timm staining band. The Timm staining of the inner molecular layer of the dentate gyrus of the hippocampus in the stimulating epilepsy group was significantly less than that in the non.

3.5.3 Accuracy of Transcranial Magnetic and Electrical Stimulation

Combining the results of clinical trial of PD and $\mathrm{AD}$, animal test of epileptic mice, our study believes that, transcranial magnetoelectricity stimulation mainly blocked the apoptotic process of neurons, its target is voltage-gated calcium channel, it activates neurotransmitter neurons, the addition of a specific pulsating electromagnetic field activates the metal cation-sharing transporter DMT1, it increases the chances of non-essential cations swinging out of neurons and eliminates inflammatory reactions.

We also analyse that, transcranial magnetic and electrical stimulation technology, the reason why transcranial magnetic stimulation can activate abnormal neurons accurately without disturbing normal neurons is that normal neurons need to release neurotransmitters to meet the following conditions: (1) There are releasable neurotransmitters, and the generation of endogenous neurotransmitters requires process and time. (2) Neurotransmitter loading into vesicles and vesicle transport need process and time. (3) There should be calcium influx. The amount of calcium influx is closely related to the concentration of calcium ion in synaptic space. (4) It is necessary to 
Table 3 Scores of seizure severity in rats pretreated with magnetoelectric stimulation at different current intensities.

\begin{tabular}{lllllllll}
\hline \multirow{2}{*}{ Group A } & \multirow{2}{*}{ Number } & \multicolumn{9}{c}{ Epilepsy seizure score } & \multicolumn{2}{c}{ Mean rank } \\
\cline { 2 - 8 } & & 0 & 1 & 2 & 3 & 4 & 5 & 26.190 \\
\hline A1(0\%MCI) & 8 & 0 & 0 & 0 & 0 & 3 & 5 & 20.380 \\
A2(25\%MCI) & 8 & 0 & 0 & 0 & 3 & 3 & 2 & 7.750 \\
A3(50\%MCI) & 8 & 0 & 2 & 4 & 1 & 1 & 0 & 11.690 \\
A4(75\%MCI) & 8 & 0 & 0 & 3 & 4 & 1 & 0 & \\
\hline
\end{tabular}

$H=19.992 ; p=0.000 ;$ MCI: Maximum current intensity.

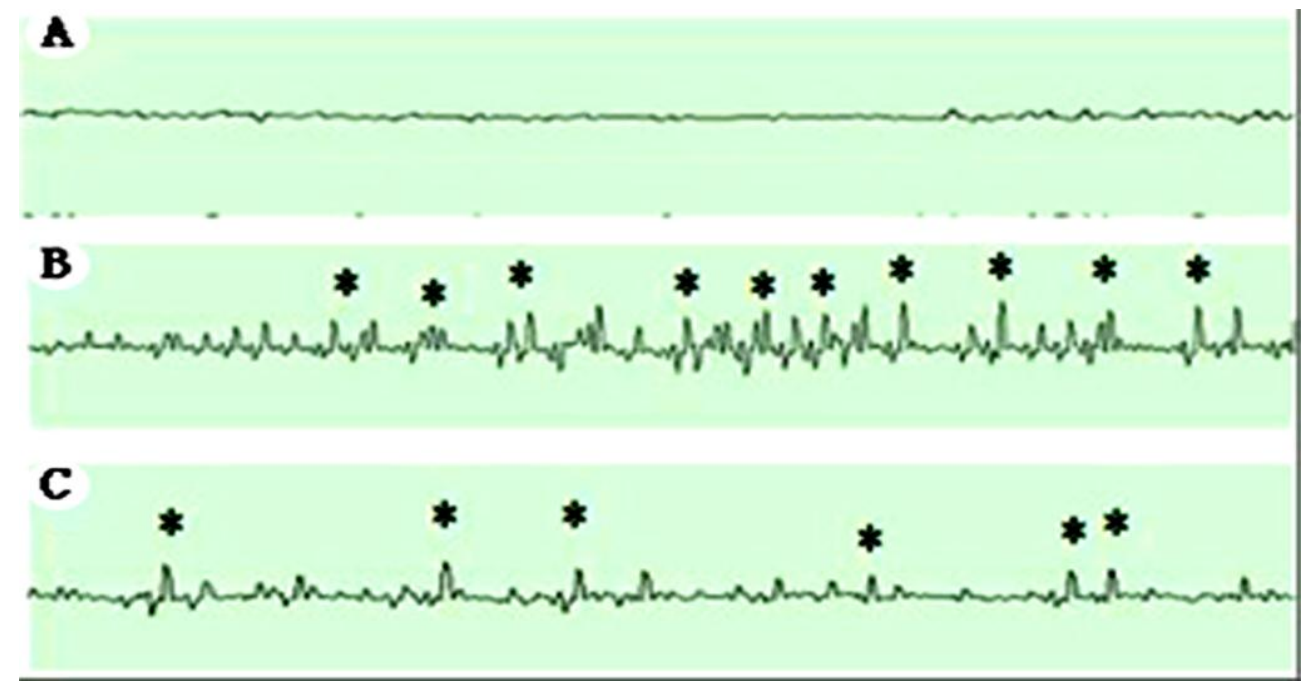

Fig. 5 EEG manifestations of Wistar rats after transcranial magnetoelectric therapy.

A: control group; B: non-stimulating epilepsy group; C: epilepsy stimulation group; * epileptic wave.

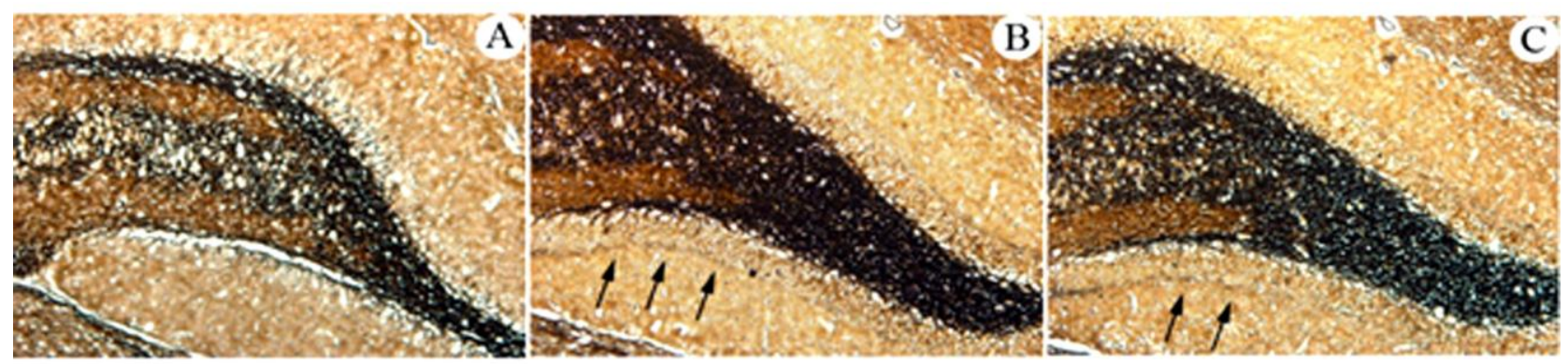

Fig. 6 Timm staining of dentate gyrus of hippocampus after 14 days of transcranial magnetic stimulation in rats $(\times 100)$.

A: control group; B: non-stimulating epilepsy group; C: epilepsy stimulation group.

maintain balance between excitation and inhibition of type II neurotransmitters in synaptic space [184-187].

External pulsating electromagnetic field does "useless work" to normal neurons which do not meet the above conditions. For normal neurons which have already met the above conditions, even without the stimulation of external electromagnetic field, the action potential generated by itself will naturally activate voltage-gated calcium channel.

\section{Conclusion}

The core viewpoint of this paper can be regarded as exploring the etiology of sporadic $\mathrm{AD}$, it is companion volume of brain cell activation theory, which is an explanation of the treatment methods and mechanism of neurodegenerative diseases such as $\mathrm{AD}$. It is suitable for encephalopathy but not limited to encephalopathy, the solution of AD should start with 
prevention and treatment, the external factor of prevention is environment, especially heavy metal ions, the internal cause is body acidity and alkalinity, physical means, especially transcranial magnetoelectricity stimulation, should be the first choice for treatment.

\section{References}

[1] Sun, Z. D. 2017. "The Theory of Brain Cell Activation." Journal of US-China Medical Science 14 (5): 203-11.

[2] Neyton, J., and Miller, C. 1998. "Discrete $\mathrm{Ba}^{2+}$ Block as a Probe of Ion Occupancy and Pore Structure in the High-conductance $\mathrm{Ca}^{2+}$-activated $\mathrm{K}^{+}$Channel." J Gen Physiol 92 (5): 569-86.

[3] Armstrong, C. M., and Binstock, L. 1965. "Anomalous Rectification in the Squid Giant Axon Injected." Journal of General Physiology 48 (5): 859-72.

[4] Armstrong, C. M., and Hille, B. 1972. "The Inner Quaternary Ammonium Ion Receptor in Potassium Channels of the Node of Ranvier." Journal of General Physiology 59 (4): 388.

[5] Mackinnon, R., and Yellen, G. 1990. "Mutations Affecting TEA Blockade and Ion Permeation in Voltage-activated $\mathrm{K}^{+}$Channels." Science 250 (4978): 276-79.

[6] Yellen, G., Jurman, M., Abramson, T., et al. 1991. "Mutations Affecting Internal TEA Blockade Identify the Probable Pore-forming Region of a $\mathrm{K}^{+}$Channel." Science 251 (4996): 939-42.

[7] Heginbotham, L., Abramson, T., and MacKinnon, R. 1992. "A Functional Connection between the Pores of Distantly Related Ion Channels as Revealed by Mutant $\mathrm{K}^{+}$Channels." Science 258 (5085): 1152-5.

[8] Liu, Y., Holmgren, M., Jurman, M. E., et al. 1997. "Gated Access to the Pore of a Voltage-Dependent K+ Channel." Neuron 19 (1): 175-84.

[9] Dong, J., and Jia, J. P. 2015. "Exploring the Etiology Hypothesis of Sporadic Alzheimer's Disease from a Genetic Perspective." Compilation of the 4th National Symposium on Dementia and Cognitive Impairment and Advanced Lectures.

[10] Kerr, M. L., and Small, D. H. 2005. "Cytoplasmic Domain of the $\beta$-amyloid Protein Precursor of Alzheimer's Disease: Function, Regulation of Proteolysis, and Implications for Drug Development." Journal of Neuroscience Research 80 (2): 151-9.

[11] Nistor, M., Don, M., Parekh, M., et al. 2007. "Alpha- and Beta-secretase Activity as a Function of Age and Beta-amyloid in Down Syndrome and Normal Brain." Neurobiology of Aging 28 (10): 1493-506.
[12] Lott, I. T., and Head, E. 2005. “Alzheimer Disease and Down Syndrome: Factors in Pathogenesis." Neurobiology of Aging 26 (3): 383-9.

[13] ALZHEIMER'S ASSOCIATION. 2015. “2015 Alzheimer's Disease Facts and Figures." Alzheimers Dement 11 (3): 332-48.

[14] Han, J. S. 2009. Neuro Science (3rd ed.). Beijing: Peking University Medical Press.

[15] Zhao, B. L., and Wan, L. 2012. "Metabolic Imbalance of Metal Ions and Early Pathogenesis of Alzheimer's Disease." Progress in Biochemisry and Biophysics 39 (8): 756-63.

[16] Laferla, F. M., Tinkle, B. T., Bieberich, C. J., et al. 1995. "The Alzheimer's A $\beta$ Peptide Induces Neurodegeneration and Apoptotic Cell Death in Transgenic Mice." Nature Genetics 9 (1): 21.

[17] Jana, A., and Pahan, K. 2004. "Fibrillar Amyloid-bcta Peptides Kill Human Primary Ncurons via NADPH Oxidase-mediated Activation of Neutral Sphingomy-clinase. Implications for Alzheimer's Disease." J Biol Chem 279 (49): 51451-9.

[18] Yang, X. H., and Jiang, Z. F. 2007. "Activation of Microglia and Alzheimer's Disease." Chemistry of Life 27 (6): 548-50.

[19] Zhu, Y. B., Lu, P. H., and Sheng, Z. H. 2008. “A New Exploration of the Pathogenesis of AD: Hypothesis of Axoplasmic Transport Obstacles." Progress in Physiological Sciences 39 (1): 5-9.

[20] Luo, H. B., Shi, X. Q., Li, Y., et al. 2013. "The Expression of Endoplasmic Reticulum a Beta Binding Protein and the Effect of Stilbene Glycoside in Behavioral Disorders Induced by a Beta in Rats." Journal of Apoplexy and Nervous Diseases 30 (2): 128-31.

[21] Qi, J., and Peng, J. X. 2004. "Degradation of Endoplasmic Reticulum-related Proteins and Its Mechanism." Chinese Journal of Cell Biology 26 (2): 103-7.

[22] Lee, M. H., Siddoway, B., Kaeser, G. E., et al. 2018. "Somatic APP Gene Recombination in Alzheimer's Disease and Normal Neurons." Nature 563: 639-45.

[23] Anand, R., Gill, K. D., and Mahdi, A. A. 2014. "Therapeutics of Alzheimer's Disease: Past, Present and Future." Neuropharmacology.

[24] Schmitz, C., Rutten, B. P. F., Pielen, A., et al. 2004. "Hippocampal Neuron Loss Exceeds Amyloid Plaque Load in a Transgenic Mouse Model of Alzheimer's Disease." American Journal of Pathology 164 (4): 1495-502.

[25] Williams, D. R. 2006. "Tauopathies: Classification and Clinical Update on Neurodegenerative Diseases Associated with Microtubule-associated Protein Tau." Internal Medicine Journal 36 (10): 652-60. 
[26] Nie, J., and Shi, J. S. 2017. "The Role of Presenilin in the Pathogenesis of Alzheimer's Disease." West China Journal of Pharmaceutical Sciences 32 (1): 99-103.

[27] Edlund, C., SöDerberg, M., and Kristensson, K. 1994. "Isoprenoids in Aging and Neurodegeneration." Neurochemistry International 25 (1): 35-8.

[28] Bu, G. 2009. "Apolipoprotein E and Its Receptors in Alzheimer's Disease: Pathways, Pathogenesis and Therapy." Nat Rev Neurosci 10 (5): 333-4.

[29] Bu, G., Liu, C. C., and Takahisa, K. 2013. "Vascular Hypothesis of Alzheimer's Disease: Role of ApoE and ApoE Receptors." Molecular Neurodegeneration 8 (Suppl 1): O20-O20.

[30] Finch, C. E., and Morgan, T. E. 2007. "Systemic Inflammation, Infection, ApoE Alleles, and Alzheimer Disease: A Position Paper." Current Alzheimer Research 4 (2): 185-9.

[31] Ashford, J. W. 2015. “Treatment of Alzheimer's Disease: The Legacy of the Cholinergic Hypothesis, Neuroplasticity, and Future Directions." Journal of Alzheimers Disease 47 (1): 149-56.

[32] Fitzgerald, R. S., Shirahata, M., Ide, T., et al. 1995. "The Cholinergic Hypothesis Revisited-An Unfinished Story.” Biological Signals 4 (5): 298-303.

[33] Meraz-Ríos, M. A., Danira, T. R., Diana, F. B., et al. 2013. "Inflammatory Process in Alzheimer's Disease." Frontiers in Integrative Neuroscience 7: 59.

[34] Frank-Cannon, T. C., Alto, L. T., Mcalpine, F. E., et al. 2009. "Does Neuroinflammation Fan the Flame in Neurodegenerative Diseases?" Molecular Neurodegeneration 4 (1): 47.

[35] Perry, V. H., Nicoll, J. A. R., and Holmes, C. 2010. "Microglia in Neurodegenerative Disease." Nature Reviews Neurology 6 (4): 193-201.

[36] Rotshenker, S. 2009. "The Role of Galectin-3/mac-2 in the Activation of the Innate-immune Function of Phagocytosis in Microglia in Injury and Disease." Journal of Molecular Neuroscience 39: 99-103.

[37] Kaur, G., Han, S. J., Yang, I., et al. 2010. "Microglia and Central Nervous System Immunity." Neurosurgery Clinics of North America 21 (1): 43-51.

[38] Luo, Y. F., Zhang, J., Liu, N. Q., et al. 2011. "Copper Ions Influence the Toxicity of $\beta$-amyloid (1-42) in a Concentration-dependent Manner in a Caenorhabditis elegans Model of Alzheimer's Disease." Sei China Life Sci 54 (6): 527-34.

[39] Hodgkin, A. L., and Huxley, A. F. 1952. "A Quantitative Description of Membrane Current and Its Application to Conduction and Excitation in Nerve." Physiol 117: 500.

[40] Hodgkin, A. L., Huxley, A. F., and Katz, B. 1952. "Measurement of Current-voltage Relations in the
Membrane of the Giant Axon of Loligo." The Journal of Physiology 116 (4): 424-48.

[41] Hodgkin, A. L., and Huxley, A. F. 1952. "A Quantitative Description of Membrane Current and Its Application to Conduction and Excitation in Verve." The Journal of Physiology 117 (4): 500-44.

[42] Bear, M. F. 2004. Neuroscience: Explore the Brain (2nd ed.). Beijing: Higher Education Press.

[43] Doyle, D. A., Morais, Cabral, J., Pfuetzner, R. A., et al. 1998. "The Structure of the Potassium Channel: Molecular Basis of $\mathrm{K}^{+}$Conduction and Selectivity." Science 280 (5360): 69-77.

[44] Nicholls, J. G., Robert, Martin, A., Fuchs, P. A., et al. 2011. From Neuron to Brain (5th ed.). England: Sinauer Associates Is an Imprint of Oxford Un.

[45] Alberts, B., Bray, D., Hopkin, K., et al. 2009. Essential Cell Biology (3rd ed.). Boca Raton: CRC Press Inc.

[46] Nuttall, J. R., and Oteiza, P. I. 2014. "Zine and the Aging Brain." Genes Nutrit 9 (1): 1-11.

[47] Luo, Y. F., Zhang, J., Liu, N. Q., et al. 2011. "Copper Ions Influence the Toxicity of $\beta$-amyloid(1-42) in a Concentration-dependent Manner in a Caenorhabditis Elegans Model of Alzheimer's Disease." Sci China Life Sci 54 (6): 527-34.

[48] Faller, P., and Hureau, C. 2009. "Bioinorganic Chemistry of Copper and Zinc Ions Coordinated to Amyloid-beta Peptide.” Dalton Trans 40 (7): 1080-94.

[49] Hung, Y. H., Bush, A. I., and Cherny, R. A. 2010. "Copper in the Brain and Alzheimer's Disease." J Biol Inorg Chem 15: 61-76.

[50] Himes, R. A., Park, G. Y., Siluvai, G. S., et al. 2008. "Structural Studies of Copper (I) Complexes of Amyloid-beta Peptide Fragments: Formation of Two-coordinate Bis(histidine) Complexes." Angew Chem Int Ed Eng1 47: 9084-7.

[51] Danscher, G., Jensen, K. B., Frederickson, C. J., et al. 1997. "Increased Amount of Zinc in the Hippocampus and Amygdala of Alzheimer's Diseased Brains: A Proton-induced X-ray Emission Spectroscopic Analysis of Cryostat Sections from Autopsy Material." J Neurosci Methods 76 (1): 53-9.

[52] Cornett, C. R., Markesbery, W. R., and Ehmann, W. D. 1998. "Imbalances of Trace Elements Related to Oxidative Damage in Alzheimer's Disease Brain." Neurotoxicology 19 (3): 339-45.

[53] Deibel, M. A., Ehmann, W. D., and Markesbery, W. R. 1996. "Copper, Iron, and Zinc Imbalances in Severely Degenerated Brain Regions in Alzheimer's Disease: Possible Relation to Oxidative Stress." J Neurol Sci 143 (1-2): 137-42.

[54] Ehmann, W. D., Markesbery, W. R., Alauddin, M., et al. 1986. "Brain Trace Elements in Alzheimer's Disease." 
Neurotoxicology 7 (1): 195-206.

[55] Samudralwar, D. L., Diprete, C. C., Ni, B. F., et al. 1995. "Elemental Imbalances in the Olfactory Pathway in Alzheimer's Disease." J Neurol Sci 130 (2): 139-45.

[56] Wenstrup, D., Ehmann, W. D., and Markesbery, W. R. 1990. "Trace Element Imbalances in Isolated Subcellular Fractions of Alzheimer's Disease Brains.” Brain Res 533 (1): 125-31.

[57] Lovell, M. A., Robertson, J. D., Teesdale, W. J., et al. 1998. "Copper, Iron and Zinc in Alzheimer's Disease Senile Plaques.” J Neurol Sci 158 (1): 47-52.

[58] Dong, J., Atwood, C. S., Anderson, V. E., et al. 2003. "Metal Binding and Oxidation of Amyloid- $\beta$ Within Isolated Senile Plaque Cores: Raman Microscopic Evidence." Biochemistry 42 (10): 2768-73.

[59] Religa, D., Strozyk, D., Cherny, R. A., et al. 2006. "Elevated Cortical Zinc in Alzheimer Disease." Neurology 67 (1): 69-75.

[60] Zhang, L. H., Wang, X., Zheng, Z. H., et al. 2010. "Altered Expression and Distribution of Zinc Transporters in APP/PS1 Transgenic Mouse Brain." Neurobiol Aging 31 (1): 74-87.

[61] Zheng, W., Wang, T., Yu, D., et al. 2010. "Elevation of Zinc Transporter ZnT3 Protein in the Cerebellar Cortex of the A $\beta P P / P S 1$ Transgenic Mouse." J Alzheimers Dis 20 (1): 323-31.

[62] Friedlich, A. L., Lee, J. Y., van, Groen, T., et al. 2004. "Neuronal Zinc Exchange with the Blood Vessel Wall Promotes Cerebral Amyloid Angiopathy in an Animal Model of Alzheimer's Disease." J Neurosci 24 (13): 3453-9.

[63] Cuajungco, M. P., and Faget, K. Y. 2003. "Zinc Takes the Center Stage: Its Paradoxical Role in Alzheimer's Disease." Brain Res Brain Res Rev 41 (1): 44-56.

[64] Bjorkdahl, C., Sjogren, M. J., Winblad, B., et al. 2005. "Zinc Induces Neurofilament Phosphorylation Independent of p70 S6 Kinase in N2a Cells." Neuroreport 16 (6): 591-5.

[65] Suh, S. W., Jensen, K. B., Jensen, M. S., et al. 2000. "Histochemically-reactive Zinc in Amyloid Plaques, Angiopathy, and Degenerating Neurons of Alzheimer's Diseased Brains.” Brain Res 852 (2): 274-8.

[66] Yokoyama, M., Koh, J., and Choi, D. W. 1986. "Brief Exposure to Zinc is Toxic to Cortical Neurons." Neurosic Lett 71 (3): 351-5.

[67] Lutsenko, S., Bhattacharjee, A., and Hubbard, A. L. 2010. "Copper Handling Machinery of the Brain." Metallomics 2: 596-608.

[68] Wang, H. Q., and Hu, H. T. 2008. "Copper and Alzheimer's Disease." Foreign Medical Sciences (Section of Medgeography) 29 (2): 57-9.

[69] Maynard, C. J., Cappai, R., Volitakis, I., et al. 2002.
“Overexpression of Alzheimer's Disease Amyloid-Opposes the Age-dependent Elevations of Brain Copper and Iron." The Journal of Biological Chemistry 277: 44670-6.

[70] Huang, X. D., Cuajungco, M. P., Atwood, C. S., et al. 1999. " $\mathrm{Cu}(\mathrm{II})$ Potentiation of Alzheimer $\mathrm{A} \beta$ Neurotoxicity." The Journal of Biological Chemistry 274: 37111-6.

[71] Lovel, M. A., Robertson, J. D., Teesdale, W. J., et al. 1998. "Copper, Iron and Zinc in Alzheimer's Disease Senile Plaques.” J Neurol Sci 158 (1): 47-52.

[72] Wang, Z. H., and Li, L. 2005. "Copper and Alzheimer's Disease.” Foreign Medical Sciences (Geriatrics) 26 (5): 205-8.

[73] Virk, S. A., and Eslick, G. D. 2015. “Aluminum Levels in Brain, Serum, and Cerebrospinal Fluid Are Higher in Alzheimer's Disease Cases than in Controls: A Series of Meta-Analyses." J Alzheimers Dis 47 (3): 629-38.

[74] Que, E. L., Domaille, D. W., and Chang, C. J. 2008. "Metals in Neurobiology: Probing their Chemistry and Biology with Molecular Imaging." Chem Rev 108 (5): 1517-49.

[75] Crapper, D. R., Krishnan, S. S., and Dalton, A. J. 1973. "Brain Aluminum Distribution in Alzheimer's Disease and Experimental Neurofi Brillary Degeneration." Science 180: 511-3.

[76] Perl, D. P., and Brody, A. R. 1980. “Alzheimer's Disease: X-ray Spectrometric Evidence of Aluminum Accumulation in Neurofibrillary Tangle-bearing Neurons." Science 208: 297-9.

[77] Yumoto, S., Kakimi, S., Ohsaki, A., et al. 2009. "Demonstration of Aluminum in Amyloid Fibers in the Cores of Senile Plaques in the Brains of Patients with Alzheimer's Disease." J Inorg Biochem 103: 1579-84.

[78] González-Domínguez, R., García-Barrera, T., and Gómez-Ariza, J. L. 2014. "Homeostasis of Metals in the Progression of Alzheimer's Disease." Biometals 27: 539-49.

[79] Cheng, S. Z., Wang, X. M., Liu, H., et al. 2012. "Experimental Study on the Pathogenesis of Aluminum-induced Alzheimer's Disease Model Rats." Journal of Apoplexy and Nervous Diseases 29 (1): 41-3.

[80] Zhu, W. Z., Zhong, W. D., Wang, W., et al. 2009. "Quantitative MR Phase-corrected Imaging to Investigate Increased Brain Iron Deposition of Patients with Alzheimer Disease.” Radiology 253 (2): 497-504.

[81] Brar, S., Henderson, D., Schenck, J., et al. 2009. "Iron Accumulation in the Substantia Nigra of Patiaents with Alzheimer Disease and Parkinsonism." Arch Neurol 66: 371-4.

[82] Xiao, F., Li, X. G., Zhang, X. Y., et al. 2011. "Combined Administration of $D$-galactose and Aluminum Induces 
Alzheimer Like Lesions in Brain." Neurosci Bull 27: 143-55.

[83] Kawahara, M., Kato, M., and Kuroda, Y. 2001. "Effects of Aluminum on the Neurotoxicity of Primary Cultured Neurons and on the Aggregation of $\beta$-amyloid Protein." Brain Research Bulletin 55 (2): 211-7.

[84] Walton, J. R., and Wang, M. X. 2009. "APP Expression, Distribution and Accumulation are Altered by Aluminum in a Rodent Model for Alzheimer's Disease." J Inorg Biochem 103 (11): 1548-54.

[85] Justin, Thenmozhi, A., William, Raja, T. R., Manivasagam, T., et al. 2017. "Hesperidin Ameliorates Cognitive Dysfunction, Oxidative Stress and Apoptosis against Aluminium Chloride Induced Rat Model of Alzheimer's Disease." Nutr Neurosci 20 (6): 360-8.

[86] Rodella, L. F., Ricci, F., Borsani, E., et al. 2008. “Aluminium Exposure Induces Alzheimer's Disease-like Histopathological Alterations in Mouse Brain." Histol Histopathol 23 (4): 433.

[87] Xie, Q., Xu, H. X., Liu, Z., et al. 2010. “T2map Imaging Study of Rat Alzheimer's Disease Model." Chinese Journal of Medical Imaging Technology 26 (s1): 114.

[88] Hutchinson, R. W., Cox, A. G., McLeod, C. W., et al. 2005. "Imaging and Spatial Distribution of Beta-amyloid Peptide and Metal Ions in Alzheimer's Plaques by Laser Ablation-inductively Coupled Plasma-mass Spectrometry." Anal Biochem 346 (2): 225-33.

[89] Sparks, D. L., and Schreurs, B. G. 2003. "Trace Amounts of Copper in Water Induce $\beta$-amyloid Plaques and Learning Deficits in a Rabbit Model of Alzheimer's Disease." J Proc Natl Acad Sci 100: 11065-9.

[90] Wang, Z. Y. 2014. "Brain Iron Metabolism Disorder Involved in the Pathogenesis and Treatment Strategy of Alzheimer's Disease." Compilation of the 24th National Congress of the Chinese Physiological Society and the Conference of Physiology.

[91] Wang, C. Y., Wang, T., Zheng, W., et al. 2010. "Zinc Overload Enhances APP Cleavage and Abeta Deposition in the Alzheimer Mouse Brain.” PLoS One 5: e15349.

[92] Lu, T., Nguyen, B., Zhang, X., et al. 1999. "Architecture of a $\mathrm{K}^{+}$Channel Inner Pore Revealed by Stoichiometric Covalent Modification." Neuron 22 (3): 571-80.

[93] Yang, J., Elllnor, P. T., Sather, W. A., et al. 1993. "Molecular Determinants of $\mathrm{Ca}^{2+}$ Selectivity and Ion Permeation in L-type $\mathrm{Ca}^{2+}$ Channels." Nature (London) 366(6451):158-161.

[94] Consiglio, J. F., Andalib, P., and Korn, S. J. 2003. "Influence of Pore Residues on Permeation Properties in the Kv2.1 Potassium Channel. Evidence for a Selective Functional Interaction of $\mathrm{K}^{+}$with the Outer Vestibule." Journal of General Physiology 121 (2): 111-24.

[95] Heinemann, S. H., Terlau, H., Stühmer, W., et al. 1992.
"Calcium Channel Characteristics Conferred on the Sodium Channel by Single Mutations." Nature (London) 356 (6368): 441-3.

[96] Palmer, A. M. 2010. "The Role of the Blood-CNS Barrier in CNS Disorders and their Treatment." Neurobiology of Disease 37 (1): 3-12.

[97] Brightman, M. W., and Reese, T. S. 1969. "Junctions between Intimately Apposed Cell Membranes in the Vertebrate Brain." J Cell Biol. 40 (3): 648-77.

[98] Wolburg, H., Noell, S., Mack, A., et al. 2009. "Brain Endothelial Cells and the Glio-vascular Complex." Cell and Tissue Research 335 (1): 75-96.

[99] Mullins, L. J. 1975. "Ion Selectivity of Carriers and Channels.” Biophysical Journal 15 (9): 921-31.

[100] Nimigean, C. M., Chappie, J. S., and Miller, C. 2003. "Electrostatic Tuning of Ion Conductance in Potassium Channels." Biochemistry 42 (31): 9263-8.

[101] Hille, B. 1973. "Potassium Channels in Myelinated Nerve: Selective Permeability to Small Cations." Journal of General Physiology 61 (6): 669.

[102] Bezanilla, F., and Armstrong, C. M. 1972. "Negative Conductance Caused by Entry of Sodium and Cesium Ions into the Potassium Channels of Squid Axons." Journal of General Physiology 60 (5): 588-608.

[103] Huxley, A. F. 2002. "Hodgkin and the Action Potential." J Physiol 538: 2.

[104] Roux, B. T. 2005. "Ion Conduction and Selectivity in $\mathrm{K}(+)$ Channels." Annual Review of Biophysics \& Biomolecular Structure 34 (34): 153-71.

[105] Han, Y. R. 2012. Molecular Cell Biology (4th ed.). Beijing: Science Press.

[106] Kuffler, S. W., and Nicholls, J. G. 1966. "The Physiology of Neuroglial Cells.” Ergeb Physiol 57 (1): 1-90.

[107] Kofuji, P., and Newman, E. A. 2004. "Potassium Buffering in the Central Nervous System." Neuroscience 129 (4): 1043-54.

[108] Kofuji, P., Ceelen, P., Zahs, K. R., et al. 2000. "Genetic Inactivation of an Inwardly Rectifying Potassium Channel (Kir4.1 Subunit) in Mice: Phenotypic Impact in Retina." The Journal of Neuroscience 20 (15): 5733-40.

[109] Madsen, E., and Gitlin, J. D. 2007. "Copper and Iron Disorders of the Brain.” Annu Rev Neurosci 30: 317-37.

[110] Wang, C., Liu, P., Wang, X. L., et al. 2008. "Metal Ions and Alzheimer's Disease." Sichuan Medical Journal 29 (4): 467-9.

[111] Phillips, R., Kondev, J., and Theriot, J. 2012. Physical Biology of the Cell. Beijing: Science Press.

[112] Doty, R. L. 2012. "Olfaction in Parkinson's Disease and Related Disorders.” Neurobiol Dis 46 (3): 527-52.

[113] Ulla, M., Bonny, J. M., Ouchchane, L., et al. 2013. "Is R2* a New MRI Biomarker for the Progression of Parkinson's Disease? A Longitudinal Follow-up." PLoS 
One 8 (3): e57904.

[114] Xu, J., Gong, D. D., Man, C. F., et al. 2014. "Parkinson's Disease and Risk of Mortalitv: Meta-analvsis and Svstematic Review." Acta Neurol Scand 129 (2): 71-9.

[115] Luckey, T. D., and Venugopal, B. 1978. "Metal Toxicity in Mammals." Chemical Toxicity of Metals and Metalloids 2: 32-36.

[116] Nichols, C. G., and Lopatin, A. N. 1997. "Inward Rectifier Potassium Channels." Annual Review of Physiology 59 (1): 171-91.

[117] Lu, Z. 2004. "Mechanism of Rectification in Inward-rectifier K ${ }^{+}$Channels." Annu Rev Physiol 66 (1): 103-29.

[118] Armstrong, C. M. 1971. "Interaction of Tetraethylammonium Ion Derivatives with the Potassium Channels of Giant Axons." Journal of General Physiology 58 (4): 413-37.

[119] Armstrong, C. M. 1966. "Time Course of TEA+-Induced Anomalous Rectification in Squid Giant Axons.” Journal of General Physiology 50 (2): 491-503.

[120] Lu, T., Ting, A. Y., Mainland, J., et al. 2001. "Probing Ion Permeation and Gating in a $\mathrm{K}^{+}$Channel with Backbone Mutations in the Selectivity Filter." Nature Neuroscience 4 (3): 239-46.

[121] Bao, H., Hakeem, A., Henteleff, M., et al. 1999. "Voltage-insensitive Gating after Charge-neutralizing Mutations in the S4 Segment of Shaker Channels." The Journal of General Physiology 113 (1): 139-51.

[122] Bruening-Wright, A., Schumacher, M. A., Adelman, J. P., et al. 2002. "Localization of the Activation Gate for Small Conductance $\mathrm{Ca}^{2+}$-activated $\mathrm{K}^{+}$Channels." The Journal of Neuroscience 22 (15): 6499-506.

[123] Korn, S. J., and Trapani, J. G. 2005. "Potassium Channels." IEEE Trans Nanobiosci 4 (1): 21-33.

[124] Flynn, G. E., Johnson, J. P. Jr., and Zagotta, W. N. 2001. "Cyclic Nucleotide-gated Channels: Shedding Light on the Opening of a Channel Pore." Nature Rev Neurosci 2: 643-52.

[125] Liu, Y., and Joho, R. H. 1998. "A Side Chain in S6 Influences both Open-state Stability and Ion Permeation in a Voltage-gated $\mathrm{K}^{+}$Channel." Pfluegers Archiv European Journal of Physiology 435 (5): 654-61.

[126] Heginbotham, L., Lu, Z., Abramson, T., et al. 1994. "Mutations in the $\mathrm{K}^{+}$Channel Signature Sequence." Biophysical Journal 66 (4): 1061-7.

[127] Schrempf, H., Schmidt, O., Kümmerlen, R., et al. 1995. "A Prokaryotic Potassium Ion Channel with Two Predicted Transmembrane Segments from Streptomyces Lividans." The EMBO Journal 14 (21): 5170-8.

[128] Heginbotham, L., Odessey, E., and Miller, C. 1997. "Tetrameric Stoichiometry of a Prokaryotic $\mathrm{K}^{+}$Channel." Biochemistry 36 (33): 10335.
[129] MacKinnon, R. 1991. "Determination of the Subunit Stoichiometry of a Voltage-activated Potassium Channel." Nature 350 (6315): 232.

[130] Ketchum, K. A., Joiner, W. J., Sellers, A. J., et al. 1995. "A New Family of Outwardly Rectifying Potassium Channel Proteins with two Pore Domains in Tandem." Nature 376 (6542): 690-5.

[131] MacKinnon, R. 1998. "Structural Conservation in Prokaryotic and Eukaryotic Potassium Channels." Science 280 (5360): 106-9.

[132] Mackinnon, R., and Miller, C. 1989. "Mutant Potassium Channels with Altered Binding of Charybdotoxin, a Pore-blocking Peptide Inhibitor." Science 245 (4924): 1382-5.

[133] Mackinnon, R., Heginbotham, L., and Abramson, T. 1990. "Mapping the Receptor Site for Charybdotoxin, a Pore-blocking Potassium Channel Inhibitor." Neuron 5 (6): 767-71.

[134] Hidalgo, P., and Mackinnon, R. 1995. "Revealing the Architecture of a $\mathrm{K}^{+}$Channel Pore through Mutant Cycles with a Peptide Inhibitor." Science 268 (5208): 307-10.

[135] Abbracchio, M. P., Burnstock, G., Verkhratsky, A., et al. 2009. "Purinergic Signalling in the Nervous System: An Overview." Trends in Neurosciences 32 (1): 19-29.

[136] Jarvis, M. F., and Khakh, B. S. 2009. “ATP-gated P2X Cation-channesl.” Neuropharmacol 56: 208-15.

[137] Skou, J. C. 1957. "The Influence of Some Cations on an Adenosine Triphosphatase from Pheripheral Nerves." Biochim Biophys Acta 23: 394-401.

[138] Caldwell, P. C., Hodgkin, A. L., Keynes, R. D., et al. 1960. "The Effect of Injecting 'Energy-rich' Phosphate Compounds on the Active Transport of Ions in the Giant Axon of Loligo." The Journal of Physiology 152 (3): 561-90.

[139] Hodgkin, A. L., and Keynes, R. D. 1955. "Active Transport of Cations in Giant Axons from Sepia and Loligo." J Physiol 128 (1): 28-60.

[140] Rizzuto, R., Pozzan, T. 2006. "Microdomains of Intracellular $\mathrm{Ca}^{2+}$ : Molecular Determinants and Functional Consequences." Physiol Rev 86 (1): 369-408.

[141] Carafoli, E., and Brini, M. 2000. "Calcium Pumps: Structural Basis for and Mechanism of Calcium Transmembrane Yransport." Curr Opin Chem Biol 4 (2): 152-61.

[142] MacLennan, D. H., Abu-Abed, M., and Kang, C. 2002. "Structure-function Relationships in $\mathrm{Ca}^{(2+)}$ Cycling Proteins." J Mol Cell Cardiol 34 (8): 897-918.

[143] Baker, P. F., Blaustein, M. P., Keynes, R. D., et al. 1969. "The Ouabain-sensitive Fluxes of Sodium and Potassium in Squid Giant Axons." J Physiol 200 (2): 459-96.

[144] Skou, J. C. 1988. "The Na,K-pump." Methods in Enzymology 156: 1-25. 
[145] Thomas, R. C. 1969. "Membrane Current and Intracellular Sodium Changes in a Snail Neuron during Extrusion of Injected Sodium.” J Physiol 201: 495-514.

[146] Thomas, R. C. 1972. "Intracellular Sodium Activity and the Sodium Pump in Snail Neurons." J Physiol 220: $55-71$.

[147] Jorgensen, P. L., Hakansson, K. O., and Karlish, S. J. 2003. "Structure and Mechanism of Na, K-ATPase: Functional Sites and Their Interactions." Annual Review of Physiology 65: 817-49.

[148] Zhao, J., Zhang, Y. M., and Zheng, N. Z. 2017. "Research Progress on Mechanism of Comorbidity of Epilepsy and Alzheimer Disease." China Medical Herald 14 (21): 53-6.

[149] Nelson, P. T., Schmitt, F. A., Lin, Y., et al. 2011. "Hippoeampal Sclerosis in Advanced Age: Clinical and Pathological Features.” Brain 134 (5): 1506-18.

[150] Palop, J. J., Chin, J., Roberson, E. D., et al. 2007. "Aberrant Excitatory Neuronal Activity and Compensatory Remodelingof Inhibitory Hippocampal Circuits in Mouse Models of Alzheimer Disease." Neuron 55 (5): 697-711.

[151] Scarmaes, N., Honig, L. S., and Choi, H. 2009. "Seizure in Alzheimer Disease: Whowhen, and How Common." Arch Network 66 (8): 435-40.

[152] Amatiniek, J. C., Hauser, W. A., DelCastillo-Castaneda, C., et al. 2006. "Incidene and Predictors of Seizures in Patients with Alzheimer Disease." Epileosia 47 (5): 867-72.

[153] Scharfman, H. E. 2012. "Alzheimer's Disease and Epilepsy: Insight from Animal Models.” Future Neurol 7 (2): 177-92.

[154] Hall, A. M., Throesch, B. T., Buckingham, S. C., et al. 2015. "Tau-dependent Kv4.2 Depiltion and Dendeitic Hyperexcitability in a Mouse Model of Alzheimer Disease." J Neurosci 35 (15): 6221-30.

[155] Glenner, G. G., and Wong, C. W. 1984. "Alzheimer's Disease and Down's Syndrome: Sharing of a Unique Cerebrovascular Amyloid Fibril Protein." Biochem Biophys Res Commun 120: 885-90.

[156] Zhao, J., O'Connor, T., and Vassar, R. 2011. “The Contribution of Activated Astrocytes to A $\beta$ Production: Implications for Alzheimer's Disease Pathogenesis." $J$ Neuroinflamm 8: 150.

[157] Citron, M., Diehl, T. S., Gordon, G., et al. 1996. "Evidence that the 42- and 40-amino Acid forms of Amyloid $\beta$ Protein are Generated from the $\beta$-amyloid Precursor Protein by Different Protease Activities." Proc Natl Acad Sci USA 93: 13170-5.

[158] Zhang, Y. W., Thompson, R., Zhang, H., et al. 2011. "APP Processing in Alzheimer's Disease." Mol Brain 4: 3.
[159] Thal, D. R. 2012. "The Role of Astrocytes in Amyloid $\beta$-protein Toxicity and Clearance." Exp Neurol 236: 1-5.

[160] Nicoll, J. A., and Weller, R. O. 2003. "A New Role for Astrocytes: $\beta$-amyloid Homeostasis and Degradation." Trends Mol Med 9: 281-2.

[161] Fu, W., Shi, D., Westaway, D., et al. 2015. "Bioenergetic Mechanisms in Astrocytes may Contribute to Amyloid Plaque Deposition and Toxicity." J Biol Chem 290: 12504-13.

[162] Nagele, R. G., D'Andrea, M. R., Lee, H., et al. 2003. "Astrocytes Accumulate A $\beta 42$ and Give Rise to Astrocytic Amyloid Plaques in Alzheimer's Disease Brains." Brain Res 971: 197-209.

[163] Wyss-Coray, T., Loike, J. D., Brionne, T. C., et al. 2003. "Adult mouse Astrocytes Degrade Amyloid- $\beta$ in Vitro and in Situ." Nat Med 9: 453-7.

[164] Batarseh, Y. S., Duong, Q. V., Mousa, Y. M., et al. 2016. "Amyloid- $\beta$ and Astrocytes Interplay in Amyloid- $\beta$ Related Disorders.” Int J Mol Sci 17: 338.

[165] Kurnellas, M. P., Adams, C. M., Sobel, R. A., et al. 2013. "Amyloid Fibrils Composed of Hexameric Peptides Attenuate Neuroinflammation." Science Translational Medicine 5 (179): 179ra42.

[166] Chemy, R. A., Legg, J. T., McLean, C. A., et al. 1999. "Aqueous Dissolution of Alzheimer's Disease A $\beta$ Amyloid Deposits by Biometal Depletion." J Biol Chem 274: 23223-8.

[167] Bush, A. I. 2002. "Metal Complexing Agents as Therapies for Alzheimer's Disease." Neurobiology of Aging 23 (6): 1031-8.

[168] Bush, A. I., and Tanzi, R. E. 2002. "The Galvanization of $\beta$-amyloid in Alzheimer's Disease." Proc Natl Acad Sci USA 99 (11): 7317-9.

[169] Lannfelt, L., Blennow, K., Zetterberg, H., et al. 2008. "Safety, Efficacy, and Biomarker Findings of PBT2 in Ttargeting $A \beta$ as a Modifying Therapy for Alzheimer's Disease: A Phase IIa, Double-blind, Randomized, Placebo-controlled Trial." Lancet Neurol 7 (9): 779-86.

[170] Storr, T., Merkel, M., Song-Zhao, G. X., et al. 2007. "Synthesis, Characterization, and Metal Coordinating Ability of Multifunctional Carbohydrate-containing Compounds for Alzheimer's Therapy." J Am Chem Soc 129 (23): 7453-63.

[171] Hamblcy, T. W. 2007. "Chemistry: Metal-based Therapeutics." Science 318 (5855): 1392-3.

[172] Cherny, R. A., Atwood, C. S., Xilinas, M. E., et al. 2001. "Treatment with a Copper-zinc Chelator Markedly and Rapidly Inhibits $\beta$-amyloid Accumulation in Alzheimer's Disease Transgenic Mice.” Neuron 30 (3): 665-76.

[173] Tang, Q., Zou, W., Sun, Z. D., et al. 2017. "Clinical Study on Transcranial Magnetoelectric Encephalopathy Treatment Instrument for Alzheimer's Disease." 
Highlights of Sciencepaper Online 10 (11): 1-7.

[174] Zou, W., Tang, Q., Sun, Z. D., et al. 2017. "Clinical Study on Transcranial Magnetoelectric Encephalopathy Treatment Instrument Treatmenting Vascular Dementia.” Beijng: ChinaXiv [2017-01-19]. DOI: 10.12074/201701.00088.

[175] Tang, Q., Zou, W., Sun, Z. D., et al. 2017. "Clinical study on Transcranial Magnetoelectric Encephalopathy Treatment Instrument Treatmenting Parkinson's Disease." Beijng: Sciencepaper Online [2017-02-08]. http://www.paper.edu.cn/releasepaper/content/201702-38.

[176] Xing, X. L., and Tang, Q. 2011. "Clinical Research on Influences of Transcranial Magnetoelectric Stimulation on Parkinson's Disease [A]." The Assembly of Conference Papers of the 11th National Rehabilitation Academic Conference of Exercise Therapy Branch of Chinese Association of Rehabilitation Medicine, Shanghai, China.

[177]Zhang, W., Wang, X. Y., Guo, H. Q., et al. 2018. "Therapeutic Effect of Repetitive Transcranial Magnetic Therapy on KA Induced Epileptic Rats." Chinese Journal of Neuromedicine 17 (7): 673-7.

[178] Xia, X. Y., Yang, Y., Bai, Y., et al. 2016. “Application of Transcranial Magnetic Stimulation Combined with Electroence-phalography in Consciousness Discrimination of Patients with Disturbance of Consciousness." Chin J Neuromed 15 (4): 425-8.

[179] Kimiskidis, V. K., Valentin, A., and Kälviäinen, R. 2014. "Transcranial Magnetic Stimulation for the Diagnosis and Treatment of Epilepsy." Curr Opin Neurol 27 (2): 236-41.
[180] Ruffolo, G., Di, B. C., Cifelli, P., et al. 2018. "A Novel Action of Lacosamide on GABAA Currents Sets the Ground for a Synergic Interaction with Levetiracetam in Treatment of Epilepsy." Neurobiol Dis 115: 59-68.

[181] Jiang, Z., Guo, M., Shi, C., et al. 2015. "Protection against Cognitive Impairment and Modification of Epileptogenesis with Curcumin in a Post-status Epilepticus Model of Temporal Lobe Epilepsy." Neuroscience 310: 362-71.

[182] Liu, A., Bryant, A., Jefferson, A., et al. 2016. "Exploring the Efficacy of a 5-day Course of Transcranial Direct Current Stimulation (TDCS) on Depression and Memory Function in Patients with Well-controlled Temporal Lobe Epilepsy." Epilepsy Behav 55: 11-20.

[183] Tang, A., Thickbroom, G., and Rodger, J. 2015. "Repetitive Transcranial Magnetic Stimulation of the Brain:Mechanisms from Animal and Experimental Models." Neuroscientist 23 (1): 1-13.

[184] Bear, M. F., Connors, B. W., and Paradiso, M. A. 2001. "Synaptic Transmission." In Neuroscience: Exploring the Brain. Philadelphia: Lippincott Williams, Wilkins Inc.

[185] Burgoyne, R. D., and Morgan, A. 2003. "Secretory Granule Exocytosis." Physiological Reviews 83 (2): 581-632.

[186] Rizo, J., Chen, X., and Arac, D. 2006. "Unraveling the Mechanisms of Synaptotagmin and SNARE Function in Neurotransmitter Release." Trends Cell Biol 16 (7): 339-50.

[187] Schneggenburger, R., and Neher, E. 2005. "Presynaptic Calcium and Control of Vesicle Fusion." Current Opinion in Neurobiology 15 (3): 266-74. 